FACULDADE DE CIÊ NCIAS ECONÔ MICAS DA UFRGS

REESTRUTURAÇÁ O DA PRODUÇÁ O AGRICOLA NO RIO GRANDE DO SUL, DE 1970 A 1996 E UMA ESTIMAÇȦ O PARA 2012 TIAGO WICKSTROM ALVES

A CRIMINALIDADE NA RECIAO METROPOLTANA DE SALVADOR JOSÉ CARRERA FERNANDEZ, LUIZ FERNANDO LOBO

COMPEIITIVIDADE INTERNACIONAL EM SOFTWARE: UM ESTUDO SOBRE A EXPERIÊNCIA DE FLORIANÓ POLIS HOVÉDO NUNES LINS

MODELOS DE ORGANIZAÇẢ O E REPARTIÇẢ O DE RENDAS NA CADEIA PRODUTIVA DO GÁS NATURAL.

HELder QUEIROZ PINTO Jú NIOR, RODOLFO TORRES dOS SANTOS

REGIMES MONETÁ RIOS E DIVIDA PÚ BLICA: UMA ANÁ LISE DE MECANISMOS ALTERNATIVOS DE COORDENAÇÃO MACROECONÓ MICA

manoel Carlos de Castro Pires

ECONOMIA DOS RECURSOS NATURAIS E SEUS INDICADORES DE ESCASSEZ: UMA QUESTÃ O DE SUSTENTABILIDADE ANDREA SALES SOARES DE AZEVEDO MELO

O ECOPROTECIONISMO AGRICOLA NA UNIĀ O EUROPEIA E SEUS POSSIVEIS IMPACTOS SOBRE A ECONOMIA BRASILEIRA Rodrigo daniel Feix, Clá udio R. Fóffano Vasconcelos

PADRÓ ES DE DESENVOLVIMENTO, FUNÇ Ó ES ESTATAIS E ENDIVIDAMENTO NO CAPITALISMO CONTEMPORÁNEO paulo Balanco, Eduardo Costa Pinto

A INTERNACIONALIZAÇÃO DO VAREJO A PARTIR DOS CASOS WAL-MART E CARREFOUR

Armando joảo dalla Costa

UMA ANÁ LISE ECONOMÉTRICA DO FUTEBOL BRASILEIRO ARI Francisco de Araujo JR, Clá udio D. SHIKIDA, LEONARDO M. MONASTERIO

O BRASIL E A ECONOMIA INTERNACIONAL: RECUPERAÇÃ O E DEFESA DA AUTONOMIA NACIONAL

RESENHA DE ALEXANDRE CÉ SAR CUNHA LEITE

REGIMES MONETÁ RIOS: TEORIA E A EXPERIÊNCIA DO REAL ResenHa de Fernando Ferrari Filho

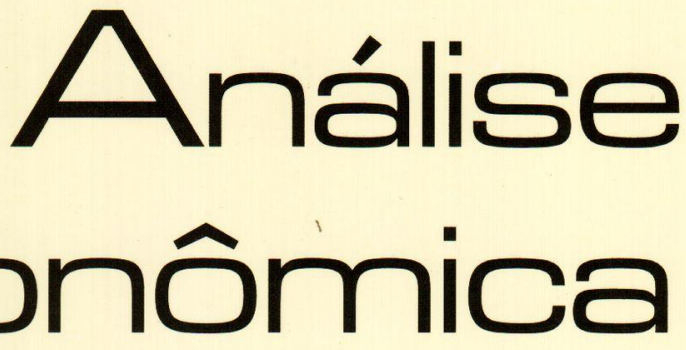


Universidade Federai. do Rio Grande do Sul Reitor: Prof José Carlos Ferraz Hemnemann

Facul dade de Cuéncias Economicas

Diretor: Prof. Gentil Corazza

Ceniro de Estudos f Prequisas Economicas

Diretor: Prof. Lovois de Andrade Miguel

Depariamenio de Crências Economicas

Chefe: Prof Ricardo Dathein

Departamento de Cîncias Coniábeis f A tuaria Chefe: Prof. Ceno Odilo Kops

Curso de Pós-Graduaçó em Economia

Coordenador: Prof. Fernando Ferrari Filho

Curso de Pos-Grainaça em Desenvolvimento RuRAI

Coordenador: Prof. Paulo Dabdab Waquil

Conseluo Eni tokial: André Moreira Cunha (UFRGS) Carlos G. A. Mielitz Netto (UFRGS), Carlos Henrique Hom (UFRGS). Eduardo A. Maldonado Filho (UFRGS). Eleutério F S. Prado (USP), Eugênio Lagemann (UFRGS), Fernando Cardim de Carvalho (UFRJ). Femando Ferrari Filho (UFRGS), Fernando de Holanda Barbosa (FGV/RJ), Flávio Augusto Ziegelmann (UFRGS), Flávio Vasconcellos Comin (UFRGS), Gentil Corazza (UFRGS), Giácomo Balbinot to Neto (UFRGS), Gustavo Franco (PUC/RJ) Hélio Henkin (UFRGS), Jan A. Kregel (UNCTAD), João Rogério Sanson (UFSC), Joaquim Pinto de Andrade (UnB), Júlio César Oliveira (UFRGS), Luiz Estrella Faria (UFRGS), Luiz Paulo Ferreira Nogueról (UFRGS), Marcelo S Portugal (UFRGS), Maria Alice Lahorgue (UFRGS), Octávio Augusto Camargo Conceicão (UFRGS), Paul Davidson (University of Tennessee), Paulo D. Waquil (UFRGS), Pedro C. D. Fonseca (UFRGS), Philip Arestis (University of Cambridge), Ricardo Dathein (UFRGS) Ronald Otto Hillbrecht (UFRGS), Sabino da Silva Porto Jr (UFRGS), Sérgio M. M. Monteiro (UFRGS), Stefano Florissi (UFRGS) e Werner Baer (University of IIIinois at Urbana - Champaign)

Comissão Emroniai: Eduardo Augusto Maldonado Filho, Fernando Ferrari Filho, Hélio Henkin. Marcelo Savino Portugal, Paulo Dabdab Waquil e Sérgio Marley Modesto Monteiro.

EnIrok: Sérgio Marley Modesto Monteiro

Ediror Adjun ro: Hélio Henkin

Secretário: Emerson Douglas Neves

REVISÃo DE IEX ros: Vanete Ricacheski

Emioração: Núcleo de Editoração e Criação da

Gráfica da UFRGS - Janaína Horn e Junia Saedt

Fundador: Prof Antonio Carlos Santos Rosa
Os materiais publicados na revista Análise Econômica são da exclusiva responsabilidade dos autores. É permitida a reprodução total ou parcial dos trabalhos, desde que seja citada a fonte. Aceita-se permuta com revistas congêneres. Aceitam-se, também, livros para divulgacão, elaboraça de resenhas e recensões Toda correspondência: material para publicação (vide normas na terceira capa), assinaturas e permutas devem ser dirigidos ao seguinte destinatário:

Prof. Sérgio Marley Modesto Monteiro Revista Andilse Económica - Av. João Pessoa, 52 CEP 90040-000 PORTO ALEGRE - RS, BRASIL Telefones: (051) $33163513 / 33164164$

Fax: (051) 33163990 - E-mail: rae@vortex ufrgs.br

A Revista Análise Econômica agradece a colaboração dos pareceristas do número 43, abaixo relacionados:

Adalmir Antonio Marquetti

André Moreira Cunha

Carlos José Caetano Bacha

Carlos Mielitz. Netto

Clailton Ataídes de Freitas

Claudio Roberto Fóffano Vasconcelos

Eduardo Ernesto Filippi

Eduardo Pontual Ribeiro

Eleuterio Fernando da Silva Prado

Fernando J Cardim de Carvalho

Fernando Augusto Mansor de Mattos

Fernando Ferrari Filho

Flávio Tosi Feijó

Flavio Vilela Vieira

Francisco Paulo Cipolla

Gentil Corazza

Gíacomo Balbinotto Neto

Helio Henkin

Jefferson Andronio Ramundo Staduto

João de Deus Sicsú Siqueira

José Carrera Fernandes

Leonardo Monteiro Monasterio

Luís Fernando de Paula

Luis Roberto Nascimento

Manoel Carlos de Castro Pires

Octavio Augusto Camargo Conceição

Patrízia Raggi Abdallah

Robson Antonio Grassi

Ronald Otto Hilbrech

Tiago Wickstrom Alves

Tito Belchior Silva Moreira

Análise Econônica

Ano 23, n ${ }^{\circ} 44$, setembro, 2005 - Porto Alegre

Faculdade de Ciências Economicas, UFRGS, 2000

Periodicidade semestral, março e setembro

1. Teoria Econômica - Desenvolvimento Regional -

Economia Agrícola - Pesquisa Teórica e Aplicada -

Periódicos. I.. Brasil

Faculdade de Ciências Econômicas,

Universidade Federal do Rio Grande do SuI

CDD 330.05

CDU $33(81)(05)$ 


\section{A criminalidade na região metropolitana de Salvador}

José Carrera Fernandez

Luiz Fernando Lobo*

Resumo: Este trabalho aborda a questão do crescimento da criminalidade na Região Metropolitana de Salvador (RMS), tomando como referência o agregado de ocorrências policiais registradas, bem como as modalidades específicas de furto e roubo e crimes contra o patrimônio. Tentando ampliar o conhecimento a respeito do fenômeno da criminalidade nessa região, este trabalho analisa, com dados em painel, a importância de um conjunto de variáveis explicativas sobre os índices de criminalidade, a partir de modelos baseados em curvas de oferta de atividades criminosas, instrumentos consagrados na teoria econômica do crime. Os resultados econométricos mostraram que o nível de educação, a eficiência da polícia, a concentração de renda, a densidade demográfica, o grau de urbanização, assim como as rendas do município e do governo municipal são importantes elementos que explicam os índices de atividade criminosa experimentados na RMS. Especificamente, expansões dos níveis de educação, das rendas do município e do governo municipal e da eficiência da polícia, assim como reduções da concentração de renda e do grau de urbanização, contribuem significativamente para reduzir a atividade criminosa na RMS.

Palavras-chave: Economia do crime, crime, criminalidade, furto e roubo.

Abstract: This paper approaches the question of increasing crime rates in the Metropolitan Region of Salvador (MRS), taking as reference the aggregate of crimes as well as the specific modalities of theft and robbery and offenses against patrimony. Trying to understand a little bit more about the phenomena of criminality in that region, this paper contains an analysis about the importance of a set of explanatory variables over these modalities of offense, using panel data and a model based on supply curves of crime, usual instruments of the economics of crime. The econometric results showed that some variables, such as level of education, police efficiency, income concentration, demographic density, urbanization, and municipality and local government income levels are important to explain the crime rates experimented in that region. Specifically, expansions of the levels of police efficiency, education, demographic density, municipality and local government incomes, as well as reductions in the levels of income

* Respectivamente, Professor da Faculdade de Ciências Econômicas da Universidade Federal da Bahia - UFBA e Ph. $\mathrm{D}^{*}$ em Economia pela The University of Chicago e Economista pela UFBA. 
concentration and urbanization, contribute significantly to reduce those crime rates in the MRS.

Keywords: Economics of crime, crime, criminality, theft and robbery.

JEL Classification: K42.

\section{Introdução}

As pesquisas mais recentes ${ }^{1}$ mostram que um dos maiores problemas que afligem os cidadãos e preocupam a opinião pública em todo o mundo é a criminalidade, superando inclusive o desemprego - pesadelo que mais tem atormentado os trabalhadores -, altas taxas de inflação, elevada carga tributária e altos custos financeiros, problemas tradicionais em qualquer país (FAJNZYLBER e ARAÚJO JR., 2001). No Brasil, essa situação não é diferente, principalmente porque a criminalidade vem quase sempre acompanhada de muita violência, além do que tem afetado todas as classes sociais, deixando de ser uma "exclusividade" das classes excluídas das periferias das grandes cidades (CARRERA-FERNANDEZ e PEREIRA, 2001). Talvez por apresentar essa triste característica, esse fenômeno tenha atraído mais a atenção da sociedade. ${ }^{2}$

O crescimento sistemático da criminalidade no país e, em particular, na Bahia, constatado através do aumento nos principais indicadores de crimes nos últimos anos, é um dos fenômenos sociais que mais tem chamado a atenção da opinião pública (CARRERAFERNANDEZ e PEREIRA, 2001). De fato, a sociedade brasileira tem reconhecido que o aparelho estatal tem falhado no cumprimento de uma de suas funções básicas, que é o de proteger os seus cidadãos contra os criminosos. Esse quadro tem estabelecido na sociedade um generalizado sentimento de insegurança e impunidade, a ponto de fazer com que os cidadãos recorram às grades para buscar a reclusão e o isolamento social, tornando-se reféns do próprio medo.

Ressalte-se que o avanço acentuado da criminalidade causa um custo para a sociedade, ao impedir o desenvolvimento normal das atividades econômicas legais. Esse custo social se dá não apenas pelo volume de recursos éconômicos roubados ou gastos em segurança pública e privada, mas principalmente pela redução da eficiên-

1 Pesquisas realizadas pelo International Centre for the Prevention of Crime nos Estados Unidos, na Europa e na América Latina (FAJNZYLBER e ARAÚJO JR., 2001).

2 O problema da criminalidade é tão latente no país que todos os candidatos à Presidência da República, demonstrando uma preocupação diferenciada com o problema, já incorporaram a seus programas de governo algumas políticas de combate a criminalidade. 
cia do setor legal da economia e da própria migração de recursos e agentes para a atividade econômica ilegal, os quais poderiam estar sendo utilizados no setor legal da economia, com ganhos para toda a sociedade. Além do mais, a criminalidade provoca uma redução na qualidade de vida da sociedade, principalmente pelos danos morais e perda de vidas que ela induz.

A ocorrência desse fenômeno na Região Metropolitana de Salvador (RMS), conforme será visto a seguir, não é muito diferente daquela experimentada em todo o país. De fato, nunca se imaginou que o aumento da criminalidade nas suas múltiplas modalidades pudesse gerar tanta preocupação na sociedade no sentido de se encontrar uma forma urgente de enfrentar esse grave problema social que aflige os baianos e os brasileiros de modo geral. Obviamente que esse aumento acentuado da criminalidade não é uma característica apenas da Bahia (CARRERA-FERNANDEZ e PEREIRA, 2001), mas se estende a todos os estados brasileiros (ARAÚJO JR. e FAJNZYLBER, 2000 e FAJNZYLBER e ARAÚJO JR., 2001), assim como afeta quase todos os países (CARRERA-FERNANDEZ e PEREIRA, 2000 e 2001, SOARES, 2001 e PEREIRA e CARRERAFERNANDEZ, 2000). No entanto, existe um certo consenso entre os estudiosos que a criminalidade no país e no estado, em particular, tem atingido proporções alarmantes, necessitando ser contida com certa urgência sob pena de esta vir a fugir do controle da segurança pública.

Os dados mostram que os índices de criminalidade na RMS são bastante altos, comparativamente aos índices apresentados em outras regiões, ou sofreram crescimento significativo nos últimos anos. Mais preocupante é que alguns municípios dessa região apresentam tendências de crescimento em seus índices, revelando uma situação extremamente grave em termos de segurança pública. Quando comparado a outras regiões, que tradicionalmente apresentam graves problemas com a criminalidade, como é caso de São Paulo, os indicadores da atividade criminosa na RMS são ainda piores. ${ }^{3}$ Para se ter uma idéia, enquanto o índice médio de crime de furto na Região Polícial da Grande São Paulo (RPGSP), que foi de 7,89 por

\footnotetext{
3 A evolução da criminalidade em Minas Gerais não é muito diferente daquela verificada na RMS. Conforme constatado por Araújo Jr. e Fajnzylber (2000), os crimes contra a propriedade aumentaram significativamente nas microregiões mineiras no período de 1986 a 1994, mas com uma queda significativa em 1995. Entre 1987 e 1994, o crime de roubo à mão armada cresceu cerca de $250 \%$, o que representa uma taxa de crescimento anual de $17 \%$. Já para a modalidade de roubo de veículo, o crescimento no período de 1991 a 1994 foi em torno de $21 \%$, o que corresponde a uma taxa de crescimento de $5 \%$ ao ano.
} 
mil habitantes em 1995, a RMS apresentou, nesse mesmo ano, um índice de furto de 10,83 por mil habitantes. Índices piores que esse são aqueles verificados em algumas cidades americanas, consideradas extremamente violentas, como foi o caso, por exemplo, de Miami $(14,66)$, Washington DC $(13,82)$ e Atlanta $(12,53)$. $O$ índice médio de furto da RMS chegou a ultrapassar aqueles verificados nas cidades de Chicago $(10,68)$, Detroit $(9,83)$, San Francisco $(8,66)$, Los Angeles $(8,15)$ e Nova York $(8,14)$, cidades tradicionalmente violentas (CARRERA-FERNANDEZ e PEREIRA, 2000).

O crescimento vertiginoso da criminalidade em todo o país tem ensejado, de certa forma, a aplicação de algumas políticas públicas de combate à criminalidade. De fato, o avanço da criminalidade no Brasil tem atraído a atenção da administração pública e da sociedade como um todo que, no afã de melhorar o nível de segurança pública, tem buscado soluções pragmáticas que tentam controlar os efeitos sem atacar as causas mais profundas do avanço da criminalidade. Existe um certo clamor por parte da sociedade no sentido de que o estado brasileiro deveria priorizar a reforma de seus códigos penal e processual penal, totalmente ultrapassados; reestruturar o poder judiciário, para torná-lo mais ágil e eficiente; ao tempo em que deveria repensar o papel e a forma de atuação das instituições policiais, reunificando-as, de modo a atender aos anseios da sociedade. O fato é que a sociedade tem clamado por penas mais duras para os criminosos, procedimentos processuais mais racionais e práticas administrativas que agilizem a justiça, para punir mais rápida e eficientemente os infratores. ${ }^{4}$

Embora todas essas medidas na área de segurança pública sejam políticas importantes, que podem efetivamente controlar os índices de criminalidade no país, outras políticas socioeconômicas são ainda mais importantes para reduzir efetivamente a criminalidade, pois atacam as suas verdadeiras causas. De fato, a maioria das políticas públicas no país nessa área tem buscado conter o aumento da criminalidade, represando as pressões sociais, estabelecendo soluções de curto prazo que combatem os sintomas e, portanto, apresentam efeitos temporários, sem levar em consideração os condicionantes que levam os indivíduos à criminalidade. Tais políti-

4 Outras medidas são também necessárias para que essas políticas atinjam seus objetivos, tais como: expansão do número de juizados e juízes, ampliando o universo de tribunais distritais, de modo a tornar a justiça mais democrática; construção de novos presídios e a melhoria dos já existentes; modernização e informatização do judiciário, principalmente as delegacias; e criação de um sistema nacional de informaçōes policiais; entre outras. 
cas têm priorizado, via de regra, consolidar a repressão policial, sem que haja uma preocupação explícita em atacar as verdadeiras causas que levam os indivíduos a migrarem para o setor do crime. ${ }^{5}$

Sob o ponto de vista teórico, ainda não existe consenso a respeito das causas do avanço da criminalidade na sociedade moderna. Uma pequena corrente de economistas acredita que o aumento da criminalidade está relacionado às características do processo capitalista e é o resultado direto das alterações do comportamento empresarial no período pós-industrial. Outra corrente mais ampla acredita que o aumento da criminalidade está associado a problemas estruturais e conjunturais. Sem dúvida que altos índices de desemprego e concentração de renda, baixos níveis de escolaridade e renda, para citar alguns, podem evidentemente agravar esse problema. É óbvio que o descaso por parte dos governos estadual e federal com as atividades típicas de estado, tais como policiamento e principalmente a justiça, tem contribuído decisivamente para o crescimento da criminalidade na quase totalidade das cidades brasileiras. Em outras palavras, existe um consenso entre os economistas de que aumentar a certeza (probabilidade de prisão e de condenação) e a severidade da punição, pode-se conter o ímpeto dos criminosos e reduzir a criminalidade.

Tentando entender um pouco mais a respeito desse preocupante fenômeno social, este trabalho analisa, sob o ponto de vista econométrico, a evolução da criminalidade na RMS, tomando-se como referência os registros de crimes de furto e roubo, crimes contra o patrimônio e o agregado de crimes, no período de 1993 a 1999. Fazendo-se uso de dados em painel, busca-se ajustar curvas de oferta de atividades criminosas, instrumentais consagrados na teoria econômica do crime, com base em modelos econométricos (linear e logit), objetivando verificar a importância de variáveis socioeconômicas na explicação desse fenômeno. A análise foi elaborada com dados disponibilizados pela SSP-BA, para os dez municípios integrantes da RMS, cobrindo o período de 1993 a 1999, além do que se estabeleceu um corte que permitiu avaliar a evolução dos índices de criminalidade

\footnotetext{
5 A prova mais contundente dessa distorção foi a promulgação do Plano Nacional de Segurança Pública (PNSP), pelo Presidente Fernando Henrique, em 2000, o qual continha 15 compromissos da ação pública apenas na área policial. É óbvio que os aparatos das polícias brasileiras estāo sucateados e desaparelhados e os seus efetivos estão cada vez menos preparados, não acompanhando o crescimento da criminalidade, tampouco houve uma melhoria da ação policial que pudesse combater o crescente avanço tecnológico da atividade criminosa no país. No entanto, além de vontade política e de significativos investimentos no aparato policial, o que é realmente necessário para resolver a problemática da criminalidade no país são políticas socioeconômicas que priorizem o cidadão.
} 
no quadriênio de 1996-99, em relação àqueles observados no triênio de 1993 a 1995.

Além dessa introdução, este trabalho está composto de mais seis seções. A segunda contém um breve sumário do estado das artes da teoria econômica do crime na atualidade, apresentando as mais importantes correntes de pensamento nessa área. $\mathrm{Na}$ seção seguinte apresenta-se uma análise da criminalidade na RMS, com base em alguns indicadores de crimes, especialmente os de furto e roubo, contra o patrimônio e o agregado de crimes registrados no período de 1993 a 1999. A quarta seção contém uma análise sucinta dos modelos econométricos utilizados neste estudo. Na seção seguinte faz-se uma descrição das variáveis utilizadas na análise econométrica, assim como são mostradas as dificuldades encontradas para obtenção de suas proxies e os problemas associados aos vieses de seleção das mesmas. Na sexta seção apresentam-se os resultados empíricos desse estudo, os quais contribuem para ampliar o conhecimento acerca da criminalidade no estado. Finalmente, a sétima seção contém as considerações finais e conclusões deste trabalho, esperando que o mesmo possa servir de suporte para outros estudos futuros.

\section{A criminalidade e a teoria econômica do crime}

Embora a criminalidade seja um tema que interessa aos economistas desde o século XVIII, demonstrado através dos trabalhos de Beccaria, Bentham e Smith (WYNARCZYK, 2000), apenas recentemente o assunto foi incorporado ao escopo da análise econômica. O trabalho interessante de Becker (1968), e o debate que se estabeleceu desde então, fez surgir uma enorme quantidade de trabalhos e uma grande diversidade de modelos econômicos, a ponto de criar um corpo próprio dentro do arcabouço da teoria econômica, estabelecendo assim as bases da economia do crime.

Até o final da década de 1960, a literatura existente sobre o crime permitia distinguir apenas uma corrente básica de pensamento. Tal corrente, denominada de biopsicossociológica, foi o resultado do desdobramento da antiga visão biológica, que foi a responsável pela formação do que hoje se costuma chamar de direito penal clássico (CARRERA-FERNANDEZ, e PEREIRA, 2000). De fato, com a evolução da análise científica, a visão biológica ampliou-se e introduziu fatores psicológicos e sociológicos como elementos importantes para a formação do caráter criminoso. O principal argumento dessa visão é que o indivíduo herda genes característicos do comportamento criminoso e, a depender do ambiente social em que o indivíduo 
se insere, tal comportamento se exterioriza, revelando o seu caráter criminoso.

Com a consolidação da teoria econômica do crime, surge uma segunda corrente de pensamento que passa a fornecer uma nova interpretação sobre o avanço da criminalidade no mundo. Segundo essa nova corrente de pensamento, os indivíduos, ao contemplarem a possibilidade de envolvimento em ações criminosas, respondem a incentivos socioeconômicos dispersos na sociedade, comportando-se de acordo com o princípio hedonístico do máximo beneficio com o mínimo esforço (CARRERA-FERNANDEZ, 1999). Nessa nova visão, a prática de crimes é uma atividade ou setor da economia e o criminoso é visto como um agente econômico (em qualquer uma das suas múltiplas formas, ou seja, empresário, investidor, trabalhador, etc.), respondendo a estímulos econômicos, mobilizando recursos produtivos, fazendo investimentos, assumindo riscos e decidindo quanto tempo alocar ao trabalho legal e/ou ilegal. Isto é, o criminoso é um verdadeiro empresário, no sentido lato da palavra, o qual objetiva maximizar lucros nesse setor ilegal da economia. A atitude dos indivíduos empresários do crime depende fundamentalmente da probabilidade de sucesso nessa atividade arriscada, a qual está relacionada aos custos e benefícios dessa atividade ilegal, relativamente às atividades legais, mas é afetada por uma série de variáveis socioeconômicas.

A terceira corrente de pensamento, de cunho institucionalista e ideológico, é bem mais recente e defende a tese de que o comportamento criminoso está vinculado às características do processo capitalista, sendo o resultado direto das alterações do comportamento empresarial ocorrido no período pós-industrial (CARRERAFERNANDEZ e PEREIRA, 2000). Os cientistas enquadrados nessa corrente de pensamento acreditam que, devido ao processo empresarial centralizador de capital e aos avanços tecnológicos resultantes, os ambientes sociais tornaram-se mais propensos às atividades criminosas (FUKUYAMA, 1999). Segundo essa linha de pensamento, o convívio social do capitalismo pós-industrial incentivou a chamada degeneração moral e, assim, permitiu o crescimento da atividade criminosa.

Por ser mais ampla que as outras correntes da literatura sobre o crime, pelo menos no que tange ao seu alcance, a teoria econômica do crime estabelece que os incentivos econômicos que levam os indivíduos a cometerem crimes estão relacionados com algumas características estruturais, adquiridas na formação do caráter dos mesmos, bem como resultam de fatores relacionados com as carac- 
terísticas e perspectivas conjunturais em que os indivíduos se inserem. Segundo essa corrente de pensamento, os níveis educacional e cultural dos indivíduos e as possibilidades de sucesso no crime características estruturais - somados às características conjunturais, permitem explicar o avanço sistemático da criminalidade nas principais regiões do país. Altos índices de desemprego e concentração de renda e baixos níveis de educação e rendimento do trabalho, somados às ineficiências das polícias e da justiça, por certo contribuíram para o crescimento e o agravamento do problema da criminalidade. Dessa forma, qualquer tentativa de implementar políticas públicas de combate à criminalidade, sem levar tais questões socioeconômicas em consideração, está fadada ao insucesso.

Os modelos econômicos sobre o crime, inseridos nessa segunda corrente de pensamento, podem ser classificados em quatro grandes grupos distintos. No primeiro, encontram-se os modelos de alocação ótima do tempo, os quais admitem que o indivíduo escolhe aplicar parte do seu tempo na atividade criminal em função da sua utilidade esperada. Dessa forma, a função de utilidade esperada do criminoso depende dos ganhos nas atividades legal e ilegal (BECKER, 1968). Admitindo a existência de uma curva de demanda por segurança por parte dos indivíduos e uma curva de oferta de crimes, Becker (1968) estabelece que os indivíduos escolhem quanto tempo eles devem alocar ao trabalho em uma atividade econômica, seja esta legal ou criminosa, de acordo com as suas preferências frente aos riscos. Dessa forma, o indivíduo decide cometer um ato criminoso se a sua utilidade esperada exceder a utilidade que ele poderia obter utilizando o seu tempo em outra atividade legal. A partir dessas hipóteses, o autor faz uso de uma curva de perdas sociais para determinar as condições ótimas e o nível resultante de crimes na sociedade, bem como os custos sociais decorrentes da criminalidade. Os trabalhos mais representativos nesse grupo são: Ehrlich (1971, 1973 e 1975), Witte (1980), Lang e Bell (1987), Ehrlich e Brower (1987), Davis (1988), Trumbull (1989), Kim, Benson, Rasmussen e Zeuhlke (1989), Sah (1991), Cornewell e Trumbull (1994), Grogger (1995), entre outros. ${ }^{6}$

\footnotetext{
6 Entre as principais contribuições oferecidas por esses estudos destacam-se: (i) a inserção do diferencial de ganho entre as atividades legal e criminal na funçāo de perdas sociais; (ii) o custo de oportunidade direto para o criminoso devido à sanção imposta; (iii) o diferencial entre o efeito causado pela detenção e o efeito causado pela pena de morte; (iv) a possibilidade de o criminoso agir concomitantemente na atividade legal e ilegal; (v) o efeito de reduçăo da atividade criminosa que poderia ser obtido com o aumento do número de promotores de justiça participando no processo investigativo; (vi) a reincidência de jovens usuários de drogas como comportamento de longo prazo, entre outras.
} 
No segundo grupo encontram-se os modelos de portfólio, os quais modelam as decisões dos indivíduos em participar do crime através da escolha de quanto de sua riqueza o indivíduo deve alocar no mercado legal e ilegal, através do envolvimento no crime, atividade arriscada (SANDMO, 1972 apud CARRERA-FERNADEZ, 1997). No terceiro grupo estão os modelos comportamentais, fundamentados em interações sociais, que tentam explicar a atividade criminal através do relacionamento social dos subgrupos, transmitindo informações e incentivando a atividade criminal. Nesse grupo estão os modelos de Furlong (1987) e Glaeser, Sacerdote $\mathcal{E}$ Scheinkman (1996).

Finalmente, no último grupo estão os modelos de migração, os quais estabelecem que os indivíduos avaliam as oportunidades disponíveis no setor legal e ilegal e migram para a atividade criminal se os ganhos esperados superarem os custos de migração, os quais incluem os custos pecuniários e não pecuniários (CARRERAFERNANDEZ, 1999). Os modelos de migração, ao reconhecer que os indivíduos não são igualmente susceptíveis ao crime, são mais amplos e dão uma dimensão moral à prática de crimes, com limitações éticas que se exteriorizam através dos custos diferenciados de migração para o crime. Esses custos diferenciados de migração fazem com que alguns agentes, que poderiam ser beneficiados ao se engajarem em atividades criminosas, não migrem para o crime. ${ }^{7}$ As principais conclusões extraídas dos modelos de migração são que os indivíduos tendem a migrar para o crime quanto maior for o diferencial entre os valores presentes dos ganhos esperados nas atividades legal e ilegal e quanto menor for o custo de migração. Nesses modelos, variações nas atitudes em relação ao crime podem ser explicadas por diferenças de percepções em relação ao futuro, assim como por diferentes perspectivas no horizonte de tempo dos agentes. Dessa forma, quanto maiores forem as taxas de desconto e os horizontes de tempo dos agentes, mais provável será a migração para a criminalidade.

Esses múltiplos modelos formam a base da teoria econômica do crime, importante corrente de pensamento econômico, que reconhece que a prática de crimes, especialmente os lucrativos, é uma atividade ou setor da economia, como qualquer outra atividade eco-

7 Nesse rol podem-se distinguir: os custos materiais (tais como equipamentos em geral, armas de fogo, veículos, entre outros), os custos psicológicos (por exemplo, sentimento de culpa, ansiedade, medo, aversão ao risco, etc.), os custos de punição esperados e os custos de oportunidade (EIDE, 2005). 
nômica tradicional. Ao postularem que os criminosos se comportam de forma racional, os quais respondem a incentivos dispersos na economia, esses modelos buscam, de alguma forma, modelar a participação dos indivíduos em atividades criminosas, objetivando estabelecer políticas de controle ao crime, identificar e mensurar o custo social do crime, analisar a melhor política de punição e avaliar a possibilidade de estratégias alternativas de reduzir a criminalidade.

Todos esses modelos geram implicações refutáveis que podem ser estudadas através da especificação de uma curva de "oferta de atividades criminosas", com uma grande aplicabilidade prática. Essa curva pressupõe que os índices de criminalidade dependem de um conjunto de variáveis independentes, consideradas explicativas, que podem ser relacionadas através de uma forma funcional. Desse modo, a maior ou menor atratividade da indústria do crime e o fluxo migratório dos indivíduos para essa atividade ilegal estão estreitamente relacionados com certas variáveis socioeconômicas, tais como escolaridade, nível de renda per capita, índice de concentração de renda, densidade demográfica e grau de urbanização, entre outras, as quais são alteradas significativamente através do processo de desenvolvimento econômico do país.

\section{A evolução da criminalidade na RMS}

Esta seção contém uma análise preliminar dos dados relativos às principais modalidades de crimes na Região Metropolitana de Salvador (RMS), por município, no período de 1993 a 1999. Essa análise dos índices de criminalidade objetiva delinear a verdadeira situação na área de segurança pública nessa importante região do estado. Os dados utilizados nessa análise são oficiais e foram obtidos da Secretaria de Segurança Pública do Estado da Bahia - SSP-BA.

A Figura 1 mostra a evolução dos principais indicadores de crimes em Salvador, município maior e mais importante da RMS, no período compreendido entre 1993 e 1999. Uma inspeção dessa figura permite constatar que, excetuando-se o crime de furto e roubo de veículos - que decresceu $11,1 \%$ nesse período --, todas as outras modalidades de crimes experimentaram um crescimento expressivo nesse período. A modalidade de crime que menos cresceu em Salvador foi a de crimes contra a pessoa, que aumentou $27,3 \%$ nesse período, o que representa uma taxa anual de crescimento de $3,5 \%$. O agregado de crimes desse município evoluiu $47,6 \%$, o que corresponde a uma taxa de crescimento de $5,7 \%$ ao ano. 
O índice de crime de furto e roubo em Salvador aumentou 51,7\% no período de 1993 a 1999, o que representa uma taxa anual de crescimento de $6,1 \%$. A evolução do índice de crimes contra o patrimônio $^{8}$ foi semelhante, ou seja, cresceu $53,4 \%$ nesse mesmo período, equivalente a uma taxa de crescimento de $6,3 \%$ ao ano. No entanto, os crimes de entorpecentes foram aqueles que mais cresceram nesse período. De fato, o índice de crimes de entorpecentes aumentou $90,9 \%$ no referido período, o que significa uma taxa de crescimento anual de $9,7 \%$. Ressalte-se que o crescimento acentuado dos indicadores dos crimes associados com narcóticos não é uma característica apenas de Salvador, mas faz-se sentir em todas as grandes capitais brasileiras. Como agravante o crescimento dos crimes de entorpecentes traz consigo uma série de outras modalidades de crimes que não seriam observados se estes não existissem ou fossem contidos a níveis mais baixos.

A evolução da criminalidade na região metropolitana como um todo não é muito diferente daquela verificada em Salvador, a qual é fortemente influenciada, ao ser ponderada, pelo seu maior e mais importante município.

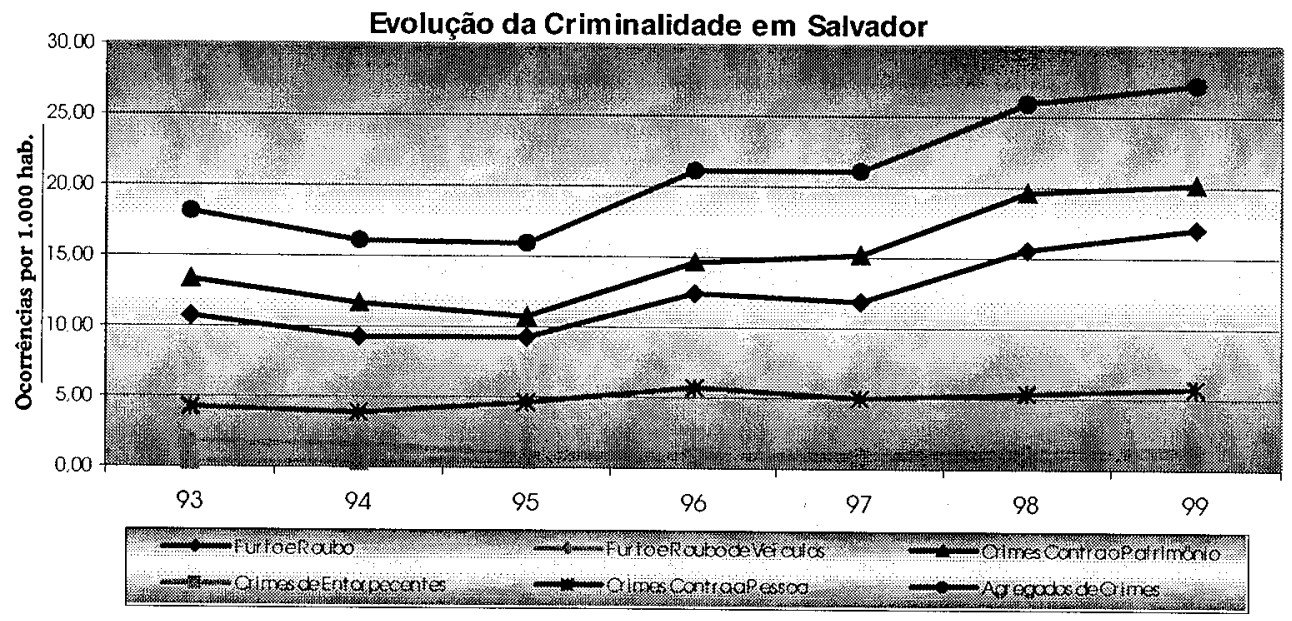

Figura 1: Evolução dos principais índices de crimes em Salvador - 1993-99.

8 Na modalidade de crimes contra o patrimônio estão inclusos os crimes furto e roubo, furto e roubo de veículos, roubo a transporte coletivo, roubo a transporte alternativo, roubo a banco, roubo em caixa eletrônico, roubo a transporte de valores, roubo de carga e latrocínio. Os crimes de entorpecentes incluem o porte, o uso e o tráfico de tóxico. 
A Figura 2 permite avaliar a evolução dos índices de furto e roubo e furto e roubo de veículos na RMS, por município, no período compreendido entre 1993 e 1999. Pode-se constatar através dessa figura que, com exceção de São Francisco do Conde, os municípios que, no início desse período, apresentavam índices menores de furto e roubo foram exatamente aqueles que apresentaram tendências de crescimento em seus índices. Em compensação, os municípios com os maiores índices no início do período foram aqueles que experimentaram reduções em seus índices, mas não apresentaram qualquer tendência de decréscimo em seus indicadores de criminalidade.
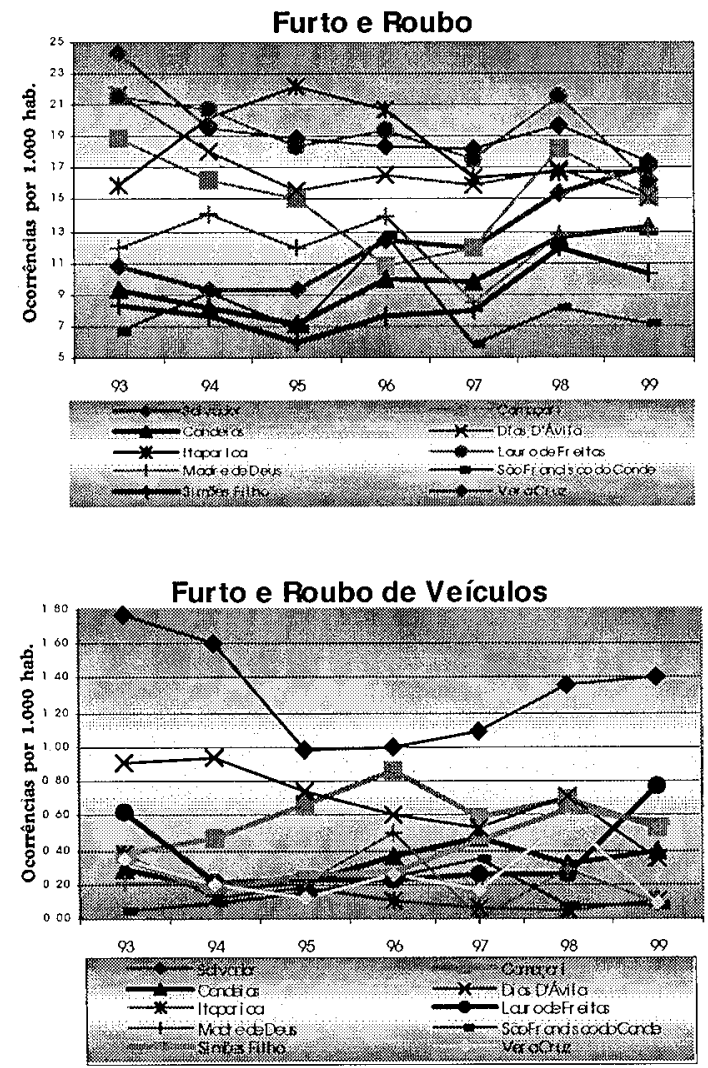

Figura 2: Evolução dos índices de furto e roubo e furto e roubo de veículos na RMS, por município - 1993-99 
De fato, a Figura 2 permite observar que os municípios de Salvador $(51,7 \%)$, Candeias $(45,2 \%)$ e Simões Filho $(37,0 \%)$, os quais apresentavam no início do período os menores índices de furto e roubo, foram exatamente aqueles que apresentaram crescimento nos seus índices de crime e revelam tendências de crescimento. Todos os outros municípios, a despeito de terem apresentado reduções em seus indicadores de crimes de furto e roubo, não mostram tendências claras de declínio em seus índices.

A Figura 3 contém a evolução dos índices de crimes contra o patrimônio e de entorpecentes na RMS, por município, no período 1993-99. Uma inspeção dessa figura revela que Salvador, Candeias e Simões Filho apresentaram crescimento significativo de seus índices de crimes contra o patrimônio, com tendências claras de crescimento. De fato, a evolução dos índices de crimes contra o patrimônio na RMS, por ser ponderada fortemente pelos índices de furto e roubo, comporta-se de forma análoga a esta última modalidade de crime.

Deve-se ressaltar que a cidade de Salvador experimentou um crescimento bastante expressivo em seus índices de crimes de entorpecentes, além do que mostra uma tendência preocupante de crescimento. Igual tendência de crescimento nessa modalidade de crime é também verificada nos municípios de Itaparica e Simões Filho.

A evolução dos índices de crimes contra a pessoa e o agregado de crimes $^{9}$ na RMS no período de 1993 a 1999, desagregado por município, pode ser vista na Figura 4. Uma análise do primeiro painel dessa figura permite observar que apenas os municípios de São Francisco do Conde e Vera Cruz apresentaram reduções em seus índices de crimes contra a pessoa. Todos os outros municípios experimentaram significativos aumentos em seus indicadores de crimes contra a pessoa, com destaque para Madre de Deus $(171,4 \%$ ) e Itaparica (133,3\%), que apresentaram tanto altos índices quanto tendências preocupantes de crescimento para essa modalidade de crime. Os municípios de Dias D’Ávila, Candeias e Camaçari, a despeito de mostrarem baixos índices de crime nessa modalidade, também mostraram tendências preocupantes de crescimento em seus indicadores de crime.

No que concerne ao agregado de crimes, pode-se constatar que Simões Filho (77,9\%), Madre de Deus $(55,0 \%)$, Candeias $(59,8 \%)$ e Salvador $(47,6 \%)$ foram os municípios que sofreram os maiores aumentos em seus índices de crimes, além do que mostraram tendências claras de crescimento.

9 Nos crimes contra a pessoa estāo os homicídios dolosos (consumado e tentado), linchamento e lesão corporal. Além de incluir todos os crimes anteriormente citados, o agregado de crimes inclui também o estupro e os crimes contra os costumes. 

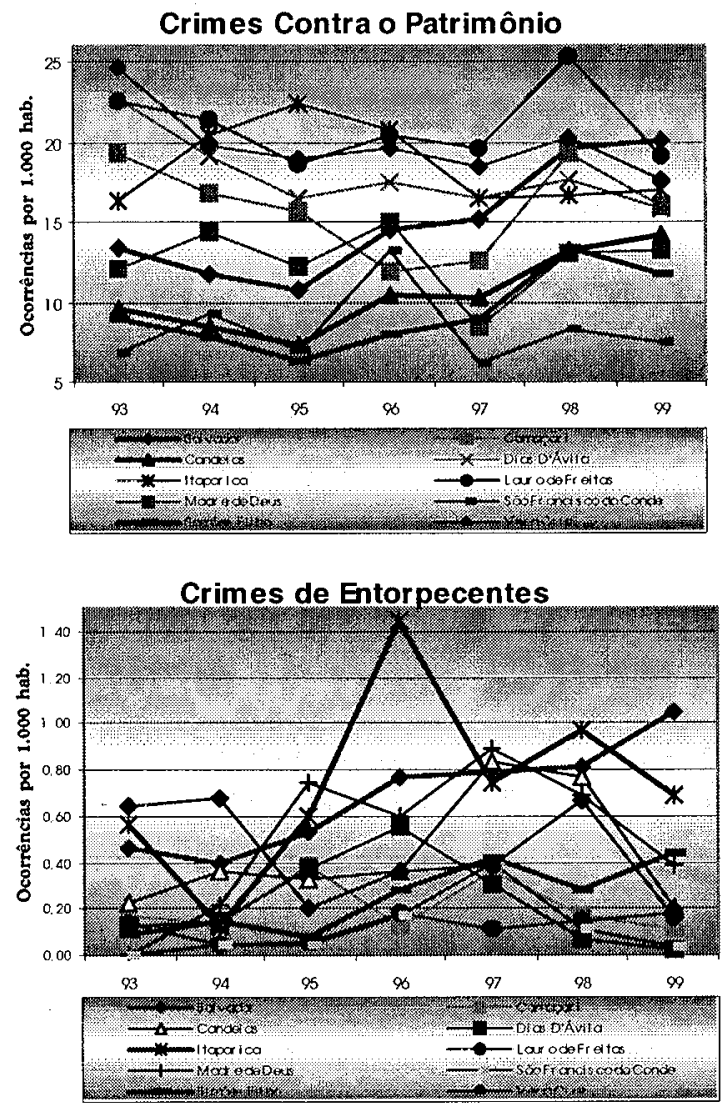

Figura 3: Evolução dos índices de crime contra o patrimônio e de entorpecentes na RMS, por município - 1993-99.

O Quadro 1 contém os índices médios de criminalidade por mil habitantes (para as modalidades de furto e roubo, crimes contra o patrimônio e o agregado de crimes) na RMS, desagregados pelo porte dos municípios (Salvador e os outros municípios), no período de 1993 a 1999. Os dados contidos nesse quadro revelam uma diferença significativa na evolução dos indicadores de criminalidade em Salvador e nos outros nove municípios integrantes da RMS.

Uma inspeção do Quadro 1 permite observar que todos os índices de criminalidade na RMS são bastante altos, com tendências crescentes para o município de Salvador, estabelecendo assim uma situação extremamente preocupante em termos de segurança pública. O índice médio de crime de furto e roubo no município de Salvador, que no triênio 1993-95 foi de 9,75 por mil habitantes, pulou 

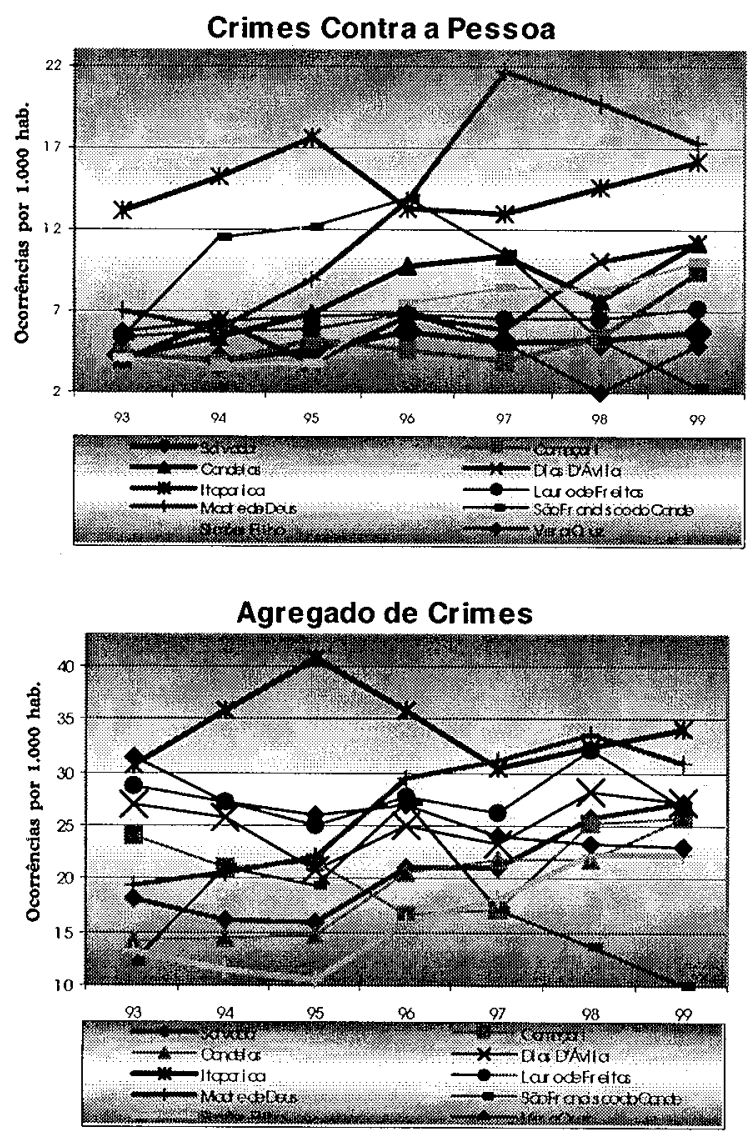

Figura 4: Evolução dos índices de crimes contra a pessoa e o agregado de crimes na RMS, por município - 1993-99.

para 14,19 no quadriênio 1996-99. Na modalidade de crime contra o patrimônio, o índice médio verificado no triênio 1993-95, que foi de 11,9 por mil habitantes, aumentou para 17,33 no quadriênio 199699. Processo semelhante aconteceu com o agregado de crimes, cujo indice cresceu de 16,73 por mil habitantes para 23,82 por mil habitantes, nesse mesmo período.

A evolução dos índices de furto e roubo nos outros municípios integrantes da RMS apresentou um processo diferenciado daquele verificado em Salvador. Isto é, o índice médio de furto e roubo desses outros municípios, que no triênio $1993-95$ foi de 14,30 por mil habitantes, caiu para 14,12 por mil habitantes no quadriênio 199699. No que concerne à evolução dos índices de crimes contra o patrimônio, houve um pequeno crescimento, de modo que o índice 
médio aumentou de 14,78 por mil habitantes para 15,20 por mil habitantes, nesse mesmo período. A despeito da redução do índice médio de furto e roubo e do pequeno aumento do índice de crimes contra o patrimônio verificado nesses nove municípios da RMS, os índices estão ainda extremamente altos e longe de serem considerados como aceitáveis. Como agravante, o índice médio do agregado de crimes nesses nove municípios menores da RMS, que no triênio $1993-95$ foi de 20,74 por mil habitantes, aumentou para 23,50 por mil habitantes, no quadriênio 1996-99, variação de $13,35 \%$ nesse período.

Quadro 1: Índices de criminalidade na RMS por 1.000 habitantes: 1993-99

\begin{tabular}{|l|ccc|ccc|ccc|}
\hline \multirow{2}{*}{ Ano } & \multicolumn{3}{|c|}{ Furto e roubo } & \multicolumn{3}{c|}{ Crime patrimonial } & \multicolumn{3}{c|}{ Crime agregado } \\
\cline { 2 - 10 } & Salvador Outros & RMS & Salvador & Outros & RMS & Salvador & Outros & RMS \\
\hline 1993 & 10,71 & 15,67 & 11,56 & 13,30 & 16,22 & 13,80 & 18,10 & 21,61 & 18,70 \\
1994 & 9,28 & 14,37 & 10,14 & 11,66 & 14,83 & 12,20 & 16,14 & 20,67 & 16,91 \\
1995 & 9,27 & 12,87 & 9,88 & 10,73 & 13,28 & 11,16 & 15,95 & 19,93 & 16,63 \\
Média (93-95) & $\mathbf{9 , 7 5}$ & $\mathbf{1 4 , 3 0}$ & $\mathbf{1 0 , 5 2}$ & $\mathbf{1 1 , 9 0}$ & $\mathbf{1 4 , 7 8}$ & $\mathbf{1 2 , 3 9}$ & $\mathbf{1 6 , 7 3}$ & $\mathbf{2 0 , 7 4}$ & $\mathbf{1 7 , 4 1}$ \\
1996 & 12,39 & 13,23 & 12,53 & 14,56 & 14,01 & 14,46 & 21,18 & 21,94 & 21,31 \\
1997 & 11,91 & $\mathbf{1 2 , 5 9}$ & 12,03 & 15,10 & 13,47 & 14,82 & 21,11 & 21,35 & 21,15 \\
1998 & 15,47 & 16,52 & 15,65 & 19,56 & 17,96 & 19,28 & 25,85 & 25,68 & 25,82 \\
1999 & 16,99 & 14,15 & 16,51 & 20,10 & 15,35 & 19,30 & 27,14 & 25,05 & 26,78 \\
Média (96-99) & $\mathbf{1 4 , 1 9}$ & $\mathbf{1 4 , 1 2}$ & $\mathbf{1 4 , 1 8}$ & $\mathbf{1 7 , 3 3}$ & $\mathbf{1 5 , 2 0}$ & $\mathbf{1 6 , 9 7}$ & $\mathbf{2 3 , 8 2}$ & $\mathbf{2 3 , 5 0}$ & $\mathbf{2 3 , 7 7}$ \\
\hline Taxa de variação & $\mathbf{5 8 , 6}$ & $\mathbf{- 1 , 2 8}$ & $\mathbf{3 4 , 7 1}$ & $\mathbf{4 5 , 6 3}$ & $\mathbf{2 , 8 6}$ & $\mathbf{3 6 , 9 8}$ & $\mathbf{4 2 , 3 6}$ & $\mathbf{1 3 , 3 5}$ & $\mathbf{3 6 , 5 0}$ \\
\hline
\end{tabular}

Fonte: Elaborado pelos autores.

Quando comparado a outras regiões, tradicionalmente consideradas como extremamente problemáticas em termos de criminalidade, como é caso de São Paulo, os índices de criminalidade da RMS não são muito diferentes. Para se ter uma idéia, enquanto o índice médio de crime de furto e roubo na Região Policial da Grande São Paulo, que em 1995 foi de 13,31 por mil habitantes (Pereira, 2000), a RMS apresentou, nesse mesmo ano, um índice de crime de furto e roubo da ordem de 9,88 por mil habitantes (Quadro 1), que, diga-se de passagem, foi o menor do triênio. Índices ainda piores foram aqueles observados nos outros nove municípios menores integrantes da RMS (sem Salvador), cuja média foi 12,87 por mil habitantes. 
A despeito dos altos índices de crimes verificados na RMS, a criminalidade nessa região se diferencia caracteristicamente daquela verificada em outras regiões do país, a exemplo de São Paulo e Rio de Janeiro. A principal diferença reside no fato de que a criminalidade na RMS não é tão empresarial e, portanto, não movimenta tantos recursos quanto nessas outras regiões, onde as organizações criminosas, alavancadas pelo tráfico de drogas, se expandiram com ramificações em todo o tecido social. No entanto, a preocupação de uma maior organização do crime na RMS sempre existe, tendo em vista que há uma certa mobilidade regional dos agentes criminosos, que migram para outras regióes na tentativa de expandirem seus negócios. Além do mais, o expressivo aumento nos crimes de entorpecentes na RMS no período entre 1993 e 1999 é um indicativo do poderio das organizações criminosas nessa região, principalmente pelo grande volume de recursos movimentado pelo narcotráfico.

Uma outra característica marcante que diferencia a criminalidade na RMS daquelas mencionadas regiões do país é que a criminalidade na RMS está mais dispersa territorialmente com poucas barreiras à ação policial, enquanto que nessas outras regiôes a criminalidade é mais concentrada em zonas de difícil acesso policial. Nesse sentido, a maior penetração policial nas zonas mais empobrecidas e dispersas da RMS permite um maior controle policial, além do que enfraquece a organização criminosa, dificultando assim que esta se desenvolva e crie ramificações maiores.

Ao compararem-se os índices de criminalidade no quadriênio 1996-99, relativamente ao triênio 1993-95 (Quadro 1), pôde-se constatar que os índices de criminalidade cresceram menos nos pequenos municípios (com menos de 150 mil habitantes), que na grande metrópole (com mais de 2 milhões de habitantes). De fato, o índice médio de furto e roubo em Salvador sofreu uma taxa de variação de $58,6 \%$ nesse período, enquanto que a taxa de variação do índice médio para os outros nove municípios menores foi de $-1,28 \%$. Fato semelhante aconteceu com os indicadores de crimes contra o patrimônio, os quais sofreram, nesse mesmo período, uma taxa de variação de 45,63\% para o município de Salvador, contra 2,86\% para os pequenos municípios. $\mathrm{O}$ agregado de crimes mostrou também padrão semelhante de evolução, exceto pelo diferencial de variação entre Salvador e os outros municípios, cuja diferença relativa não foi tão grande quanto nas outras duas modalidades de crimes.

No entanto, deve-se ressaltar que os índices médios de criminalidade nos outros nove municípios integrantes da RMS, no triênio 1993-95, foram mais altos do que aqueles apresentados em 
Salvador. Dessa forma, pôde-se constatar que o maior crescimento dos índices de criminalidade em Salvador, relativamente aos outros municípios integrantes da RMS, colocou os indicadores desse município em pé de igualdade com os dos outros municípios menores ou, para algumas modalidades de crimes, ainda piores. Registre-se que essa evidência contraria o resultado encontrado por CarreraFernandez $\mathcal{E}$ Pereira (2000) para o resto do estado da Bahia, ou seja, sem a RMS, os quais observaram que a criminalidade cresceu mais nos municípios menores (com menos de 100 mil habitantes), tradicionalmente mais tranqüilos. ${ }^{10} \mathrm{O}$ fato de os municípios com menores índices de criminalidade apresentarem maiores taxas de crescimento parece evidenciar que os indicadores de criminalidade no estado da Bahia tendem a se equalizar no seu patamar mais alto, revelando uma situação extremamente preocupante.

\section{Os modelos econométricos}

Esta seção analisa os procedimentos econométricos utilizados para correlacionar os dados referentes aos índices de criminalidade com as variáveis socioeconômicas. A possibilidade de tais correlações será inicialmente modelada de acordo com a oferta determinística de crimes, a qual está fundamentada nos modelos econômicos de comportamento dos indivíduos frente ao crime.

Um modelo bastante disseminado na teoria econômica do crime é a alocação ótima do tempo entre atividades legais e ilegais (BECKER, 1968). Nesse modelo, os indivíduos escolhem quanto tempo alocar ao trabalho em uma atividade econômica, seja esta legal ou criminosa, de acordo com as suas preferências frente aos riscos de ser capturado e condenado. Obviamente que o indivíduo decide cometer um ato criminoso se a sua utilidade esperada exceder a utilidade que ele poderia obter utilizando o seu tempo em outra atividade legal. A oferta de atividades criminosas é estabelecida de acordo com certos incentivos socioeconômicos e preferências indi-

10. Embora esse resultado revele uma certa deterioração das condiçōes de vida nas pequenas cidades do restante do estado da Bahia, em termos de segurança pública, ele deve ser visto com certa cautela. Isso porque, nos municípios maiores, um grande número de ocorrências policiais não é registrado, fato esse que decorre do próprio descrédito que os cidadãos depositam nas suas polícias. Essa grande proporção de crimes não registrados não é tão significativa nos municípios de pequeno porte, onde o aparato policial exerce uma maior integração com os munícipes, levando-os a registrar sistematicamente todas as suas ocorrências policiais. De fato, a melhoria nas relaçōes institucionais, o que seguramente aconteceria com uma maior integração policial na comunidade, tende a melhorar a confiança dos munícipes no sistema, aumentando assim a proporção de registros policiais. Esse aumento no número de registros, por outro lado, tende a melhorar o mecanismo de informação do próprio sistema de segurança pública. 
viduais, os quais se exteriorizam através da alocação do tempo à prática de crimes.

De fato, os modelos apresentados na segunda seção formam a base da teoria econômica do crime e geram implicações refutáveis que podem ser estudadas através da especificação de uma curva de "oferta de atividades criminosas". Essa curva pressupõe que os índices de criminalidade dependem de um conjunto de variáveis independentes, consideradas explicativas, que podem ser relacionadas através do seguinte modelo linear:

$$
c=\beta X+e
$$

onde $c$ representa o índice de criminalidade; $X$ é o vetor de variáveis independentes, que pretensamente afeta tal índice de criminalidade; $e$ é o termo aleatório que representa os possíveis erros de medida da variável dependente, bem como todos os demais fatores não explicitados na equação, o qual se admite ser distribuído normalmente com média zero e variância $\sigma^{2}$; e $\beta$ é o vetor de parâmetros a ser estimado.

Objetivando ampliar o conhecimento a respeito da criminalidade na RMS, analisa-se também a correlação, em termos probabilísticos, de algumas variáveis socioeconômicas com a variabilidade dos índices de criminalidade verificados nessa região, no período de 1994 a 1999. Assim, visando verificar como os indicadores de criminalidade variam através do tempo, ou seja, de um período $t$ para um período $t+k$, supõe-se que a oferta de crimes no período $t, c_{t}$, é especificada por:

$$
c_{t}=\beta_{h} h+\beta_{k} k+v
$$

onde $h$ e $k$ são dois vetores que contêm conjuntos distintos de fatores e/ou atributos socioeconômicos que determinam essa oferta; $\beta_{h}$ e $\beta_{k}$ são os respectivos conjuntos de parâmetros associados a esses vetores; e $v$ é a perturbação aleatória.

Admite-se que a oferta de crimes em um período subseqüente $t+k, c_{t+k}$, pode ser expressa através do seguinte modelo:

$$
c_{t+k}=\gamma_{h} h+\gamma_{q} q+\xi
$$

onde $q$ é um vetor contendo um conjunto de variáveis que afeta essa função de oferta; $\gamma_{q}$ é o correspondente conjunto de parâmetros desse vetor; e $\xi$ é a perturbação aleatória. Vale ressaltar que as variáveis contidas no vetor $h$ afetam concomitantemente a oferta em ambos os períodos. 
Associando-se a variabilidade dessas curvas de oferta de crimes a uma variável binária $y$, então quando $c_{t+k} \geq c_{t}$, essa variável assume o valor unitário, e quando $c_{t+k}<c_{t}$, o seu valor será zero. Assim, tomando a diferença entre as equações (4.3) e (4.2), pode-se então expressar a probabilidade de aumentos nos índices de criminalidade através da seguinte expressão:

$$
\operatorname{Pr}(y=1)=G\left[\left(\beta_{h}-\gamma_{h}\right) \dot{h}+\beta_{k} k-\gamma_{q} q+v-\xi \geq 0\right]=F(v X)
$$

assim como para a probabilidade de reduções nesses índices:

(4.5) $\operatorname{Pr}(y=0)=1-G\left[\left(\beta_{h}-\gamma_{h}\right) h+\beta_{k} k-\gamma_{q} q+v-\xi<0\right]=1-F(v X)$

onde $F(n C)$ é a função de distribuição cumulativa de probabilidade. O problema então é encontrar uma relação funcional apropriada para as distribuições de probabilidade acima, que preveja predições consistentes, ademais de garantir que:

$$
\begin{aligned}
& \lim _{v X \rightarrow+\infty} \operatorname{Pr}(\mathrm{y}=1)=1 \\
& \lim _{v X \rightarrow+\infty} \operatorname{Pr}(\mathrm{y}=0)=0
\end{aligned}
$$

Uma relação funcional simples que apresenta tais propriedades é a função logística: ${ }^{11}$

$$
\begin{aligned}
& \operatorname{Pr}(y=1)=e^{v X} /\left(1+e^{v X}\right)=F(v X) \\
& \operatorname{Pr}(y=0)=1 / /\left(1+e^{v X}\right)=1-F(v X)
\end{aligned}
$$

Assim, tomando-se a razão dessas probabilidades e aplicandose o logaritmo neperiano em ambos os lados, resulta o modelo logit a ser estimado:

$$
z=v X+\varepsilon
$$

"As formas funcionais mais comuns, além da logit, são a linear e a probit, cujas especificaçōes são, respectivamente:

$$
\begin{aligned}
& F(v X)=v X \\
& F(v X)=\Phi(v X)=\int_{-\infty}^{v X}(1 / 2 \pi)^{1 / 2} e^{-t^{2} / 2} d t
\end{aligned}
$$

onde $\Phi(v X)$ representa a função de densidade normal cumulativa. 
onde $z$ é uma variável dummy, observável, que assume apenas dois valores: unitário se a variação do índice de criminalidade é positiva, e zero caso contrário; $v$ é o vetor de parâmetros, a ser estimado; $X$ é um conjunto de variáveis de controle que afetam o índice de criminalidade; e $\varepsilon$ é a perturbação aleatória.

O modelo logit é apropriado para verificar até que ponto as condições socioeconômicas podem efetivamente explicar as variações anuais dos indicadores de criminalidade, tanto em nível agregado quanto para as modalidades específicas de furto e roubo e crimes contra o patrimônio.

\section{Definição das variáveis e proxies utilizadas}

As informações utilizadas neste estudo abrangem os dez municípios integrantes da Região Metropolitana de Salvador, no período de 1993 a 1999. Os dados referentes à criminalidade foram disponibilizados pelo Centro de Documentação e Estatística Policial (CEDEP) da Secretaria de Segurança Pública do Estado da Bahia (SSP-BA), enquanto que os dados socioeconômicos utilizados neste estudo foram extraídos da Pesquisa de Informações Municipais e do Anuário Estatístico da Bahia, os quais são publicados periodicamente pela SEI.

É importante ressaltar que os crimes contra o patrimônio englobam os crimes de furto e roubo, furto e roubo de veículos, roubo a transportes coletivo e alternativo, roubo a bancos e a caixas eletrônicos, roubo a transporte e roubo de cargas. O agregado de crimes, além dos crimes contra o patrimônio, contabiliza os crimes de entorpecentes, crimes contra a pessoa (homicídios tentado e consumado, linchamento e lesão corporal) e crime de estupro.

A proxy utilizada para caracterizar a eficiência da polícia foi a proporção do número de detidos no total de ocorrências policiais registradas no município. Deve-se salientar, entretanto, que a eficiência da polícia pode ser avaliada de diferentes formas. No entanto, a principal característica da eficiência policial relaciona-se com o número de detidos sob a vigilância da instituição. ${ }^{12} \mathrm{Um}$ bom indicador para a eficiência da polícia seria a proporção de crimes resolvidos ou solucionados no total de registros policiais. O efetivo policial também tem sido utilizado por alguns pesquisadores como proxy para a eficiência da polícia. Infelizmente, não foram disponibilizadas essas informações.

12 Algumas estimativas norte-americanas mostram que os jovens são detidos a cada seis crimes cometidos, o que significa uma probabilidade de detenção de quase 17\% (FREEMAN, 1996).

Essa estimativa serve perfeitamente para caracterizar a eficiência da policia americana. 
É importante registrar as dificuldades que o pesquisador encontra para obter dados de boa qualidade no Brasil, principalmente quando estes são sobre crimes. A qualidade dos dados de crimes no país já é um problema em si, tendo em vista que uma grande parte das ocorrências policiais não é registrada pelos cidadãos. Essa prática é, via de regra, motivada pelo próprio descrédito que os cidadãos depositam nas suas polícias, os quais acreditam que o registro acabará sendo inócuo, além do que terão que se submeter ao próprio ambiente, nada agradável, de uma delegacia de polícia. Devese ressaltar, entretanto, que esse problema é mais grave nos municípios maiores, como é o caso de Salvador, onde muitas ocorrências deixam de ser registradas, simplesmente porque os cidadãos não acreditam que a sua queixa venha a ser apurada pela polícia. Esse fenômeno não é tão significativo nos municípios de pequeno porte, onde o aparato policial exerce uma maior integração com os munícipes, levando-os a registrar sistematicamente todas as suas ocorrências policiais. ${ }^{13}$

Esses erros de medição, que resultam da subdenúncia, são agravados pelos problemas de sub-registros policiais. Isto é, os erros de medição se ampliam porque, na tentativa de demonstrar um total controle do governo na área da segurança pública, a administração pública utiliza vários procedimentos para subestimar as informaçōes sobre o crime. Sạo vários os artifícios utilizados pelos órgãos especializados que caracterizam essa prática Por exemplo, um furto de veículo que é detectado pela polícia e acaba com os seus ocupantes mortos em tiroteio, aparece nas estatísticas apenas como um caso de furto e roubo de veículos.

Para a mensuração do nível de educação do município, tomouse o número de matrículas do ensino fundamental e do ensino secundário (ou seja, primeiro e segundo graus) per capita. A densidade demográfica de cada município foi definida pela divisão da população residente pela área, em $\mathrm{km}^{2}$, de cada município. O grau de urbanização do município foi avaliado pela participação da população urbana na população total do município.

Tomou-se como proxy para a renda do município o PIB municipal per capita. A renda do governo municipal foi utilizada como estimativa para o tamanho do governo municipal, a qual foi definida pela sua arrecadação e repasses dos governos estadual e federal per capita.

${ }^{13}$ A melhoria das relações institucionais da polícia com as comunidades tende a melhorar a confiança dos munícipes no sistema, o que seguramente aumentaria o número de registros policiais e melhoraria o mecanismo de informação do próprio sistema. 
Os dados monetários utilizados nesta pesquisa foram deflacionados para reais de 1999, utilizando-se o índice geral de preços - demanda interna (IGP-DI). Quanto ao PIB municipal, usou-se o índice de volume do PIB como deflator, procedimento comumente utilizado pela SEI.

A proxy utilizada para a concentração de renda foi estabelecida pela relação entre o número de veículos e o consumo residencial de energia elétrica. Sabe-se que um aumento generalizado da renda aumenta tanto o número de veículos quanto o consumo de energia elétrica. No entanto, uma melhoria da renda do setor mais empobrecido da sociedade relativamente às camadas mais privilegiadas, o que reduz a concentração de renda, aumenta mais o consumo de energia elétrica que o número de veículos. A intuição por trás dessa proxy é que as camadas menos privilegiadas da sociedade, por não disporem de todos os aparelhos eletro-eletrônicos, iniciam suas escaladas de consumo através desses aparelhos, que tendem a aumentar mais o consumo de energia elétrica que o número de veículos. Por outro lado, um aumento da renda da camada mais privilegiada aumenta mais o número de veículos que o consumo de energia elétrica, tendo em vista que as camadas mais ricas da sociedade já dispõem de todos os aparelhos eletro-eletrônicos.

Estudos econométricos revelam que a eficiência da polícia é negativamente correlacionada com os índices de crimes. Utilizando dados da Região Policial da Grande São Paulo, Carrera-Fernandez e Pereira (2001) encontraram estimativas para elasticidades da eficiência da polícia que variaram de $-0,083$, para crimes agregados, a $-0,857$, para roubo. A maioria dos estudos sobre a criminalidade nos EUA estima que as elasticidades da probabilidade de detenção, proxy para a eficiência da polícia, variam de $-2,116$ até $-0,0212$. As estatísticas americanas revelam que cada prisioneiro adicional elimina anualmente cerca de 0,004 assassinatos, um vigésimo de um rapto, e entre dois e três outros crimes violentos. No entanto, a maior parte da redução da criminalidade ocorreria nos pequenos crimes contra a propriedade. Utilizando dados americanos, Levit (1994) estimou que um novo encarceramento reduz aproximadamente 13 crimes por ano. Igualmente, Marvell e Moody (1994, apud, Levit, 1994) estimaram que, nos anos 1970 e 1980 , cada prisioneiro estadual adicional evitou no mínimo 17 crimes. Segundo os mesmos autores, esse número na década de 1990 seria ainda maior, em cerca de 21.

Espera-se que a renda do município, indicador para o rendimento das pessoas, seja negativamente correlacionada com os índices de criminalidade. Alguns trabalhos evidenciam que rendimen- 
tos mais altos tendem a reduzir o número de detenções ou condenações relacionadas a crimes contra o patrimônio. Witte (1980) comprovou esse fato, ao detectar que salários mais altos são mais eficientes em conter a criminalidade, principalmente quando se trata de delinqüentes que cometem crimes violentos.

A despeito de não se dispor de muita evidência empírica a respeito do efeito dos níveis de concentração de renda sobre a criminalidade, os estudos disponíveis sugerem que níveis mais altos de concentração de renda estão positivamente correlacionados com níveis maiores de criminalidade (EHRLICH, 1973; CHIRICOS 1987, apud FREEMAN, 1996; WONG, 1995; MAGALHĀES, 1997; ARAÚJO JR. e FAJNZYLBER, 2000; FAJNZYLBER e ARAÚJO JR., 2001; SOARES, 2001; e CARRERA.FERNANDEZ e PEREIRA, 2001).

\section{Os resultados}

O Quadro 2 contém os resultados das curvas de oferta de crimes (modelo 4.1) nas modalidades de furto e roubo, crimes contra o patrimônio e agregado de crimes da RMS. Pode-se observar que todas as variáveis explicativas relacionadas nesse quadro apresentaram, para os três tipos de crime analisados, sinal correto de acordo com o esperado, além do que foram estatisticamente significativas.

Deve-se ressaltar que algumas variáveis socioeconômicas não foram incluídas no vetor de regressores, pois, uma vez testadas, mostraram-se estatisticamente não significativas para explicar a criminalidade na RMS. A propósito, as várias proxies utilizadas para representar a eficiência da justiça ${ }^{14}$ não se mostraram estatisticamente significativas e, em alguns casos, mostraram-se positivamente correlacionadas com os índices de criminalidade, contrariando o sinal esperado. ${ }^{15}$ Esse resultado acaba por revelar uma situação preocupante, em termos de segurança pública, tendo em vista que a justiça - instituição que tradicionalmente refreia os ímpetos dos criminosos, através da aplicação de penas de reclusão - não tem conseguido, pelo menos na RMS, se fazer sentir contendo o avanço da criminalidade.

4 Uma proxy utilizada foi a proporção de ordens judiciais de prisōes no total de ocorrências policiais. A outra foi a proporção do numero de prisões por ordem judicial na despesa do município com o judiciário.

15 Os resultados econométricos existentes revelaram que a elasticidade da eficiência da justiça pode variar de -0,02408 a -0,714 (TRUMBULL, 1989, WONG, 1995, EHRLICH, 1973 e 1975, EHRLICH e BROWER, 1987 e WITTE, 1980). No entanto, outros estudos mostram que não tem havido uma redução acentuada da criminalidade em resposta ao aumento no número de condenaçōes e aprisionamentos judiciais. 
Por outro lado, a eficiência da polícia mostrou-se estatisticamente significativa e negativamente correlacionada com as três modalidades de crime, mostrando que o desempenho policial é, de fato, uma forma efetiva de combate ao crime. Esse resultado já era, de certa forma, esperado, tendo em vista que a polícia baiana, por mais desestruturada e desaparelhada que seja, é efetiva e faz realmente a diferença. ${ }^{16} \mathrm{~A}$ prova mais contundente desse resultado foi a situação de caos por que passou a RMS com a greve da polícia, em 2001. Infelizmente, o mesmo não pôde ser dito a respeito da eficiência da justiça, a qual não se mostrou efetiva em reduzir a criminalidade.

A concentração de renda foi estatisticamente significativa e positivamente correlacionada com a criminalidade nos três tipos de crime, indicando que o aumento da concentração de renda aumenta, de fato, a criminalidade. ${ }^{17}$ Padrão semelhante de correlação foi verificado em relação ao grau de urbanização, indicando que a maior concentração urbana contribui para aumentar a atividade criminosa. Esse fato comprova a eficácia de políticas que favorecem a fixação da população no campo ou estabelecem condições para redirecionar as pessoas para as áreas rurais, como é o caso específico da reforma agrária.

A densidade demográfica, por outro lado, revelou-se estatisticamente significativa e negativamente correlacionada com todas as modalidades de crime analisadas, indicando que a maior concentração de pessoas por quilômetro quadrado tende a reduzir os índices de criminalidade. Esse fato acaba por revelar que os municípios com maior densidade demográfica são também aqueles que apresentam, em termos relativos, os menores índices de crimes. Esse resultado deve ser visto com certa cautela por dois motivos. Primeiro, porque ele pode estar sendo afetado pela correlação positiva entre a efetividade da polícia e a densidade demográfica, a qual é maior quanto mais denso demograficamente é o município. O segundo motivo é que existe um viés natural para baixo nos registros policiais, que ocorre pelo descredito dos cidadãos com a polícia, o qual é maior quanto maior é a densidade populacional.

O nível de renda do município, proxy para o seu grau de desenvolvimento, mostrou-se estatisticamente significativo e negativamente

\footnotetext{
16 Estudos recentes para a Região Policial da Grande São Paulo, com séries temporais, revelaram que a eficiência da polícia é fracamente correlacionada com o índice agregado de crimes, significando que o efeito dessa variável sobre o crime agregado não é tão grande quanto se espera (CARRERA-FERNANDEZ e PEREIRA, 2000).

i7 Com dados para o estado da Bahia, Carrera-Fernandez e Pereira (2001) constataram um "efeito Robin Hood", no sentido de que a maior concentração de renda contribui para aumentar a probabilidade de incrementos na criminalidade em geral.
} 
Quadro 2: Resultados do modelo linear para as curvas de oferta de crimes da região metropolitana de Salvador

\begin{tabular}{|c|c|c|c|c|}
\hline Variáveis & $\beta$ & Desvio Padrão & Estatística t & $\operatorname{Sig} \mathbf{t}$ \\
\hline \multicolumn{5}{|l|}{ FURTOE ROUBO } \\
\hline Eficiência da polícia & $-7,3480$ & 2,193 & $-3,350$ & 0,001 \\
\hline Concentração de renda & 47,4280 & 17,796 & 2,665 & 0,010 \\
\hline Nível de educação & $-28,6740$ & 7,064 & $-4,059$ & 0,000 \\
\hline Densidade demográfica & $-0,0039$ & 0,001 & $-5,029$ & 0,000 \\
\hline Grau de urbanizaçāo & 10,2340 & 3,300 & 3,102 & 0,003 \\
\hline Renda do municipio & $-0,0001$ & 0,000 & $-3,169$ & 0,002 \\
\hline Renda do governo municipal & $-0,0011$ & 0,001 & $-1,898$ & 0,062 \\
\hline Constante & 19,152 & 3,634 & 5,271 & 0,000 \\
\hline \multicolumn{5}{|c|}{$N=70 ; \quad R^{2}=0,582 ; \quad F=12,349 ; \quad$ Sig $F=0.000$} \\
\hline \multicolumn{5}{|c|}{ CRIME CONTRA O PATRIMÔNIO (método ENTER) } \\
\hline Eficiência da policia & $-7,9600$ & 2,293 & $-3,472$ & 0,001 \\
\hline Concentração de renda & 56,2950 & 18,605 & 3,026 & 0,004 \\
\hline Nivel de educação & $-28,2670$ & 7,385 & $-3,828$ & 0,000 \\
\hline Densidade demográfica & $-0,0034$ & 0,001 & $-4,203$ & 0,000 \\
\hline Grau de urbanização & 10,0010 & 3,449 & 2,899 & 0,005 \\
\hline Renda do município & $-0,0001$ & 0,000 & $-2,640$ & 0,010 \\
\hline Renda do governo municipal & $-0,0011$ & 0,001 & $-1,881$ & 0,065 \\
\hline Constante & 19,308 & 3,799 & 5,083 & 0,000 \\
\hline \multicolumn{5}{|c|}{$N=70 ; \quad R^{2}=0,579 ; \quad F=12,18 ; \quad$ Sig $F=0000$} \\
\hline \multicolumn{5}{|l|}{ CRIME AGREGADO } \\
\hline Eficiéncia da polícia & $-16,4640$ & 3,189 & $-5,162$ & 0,000 \\
\hline Concentração de renda & 83,9310 & 30,172 & 2,782 & 0,008 \\
\hline Nivel de educação & $-93,4790$ & 44,778 & $-2,265$ & 0,042 \\
\hline Densidade demográfica & $-0,0052$ & 0,001 & $-4,216$ & 0,000 \\
\hline Grau de urbanização & 17,5440 & 5,133 & 3,418 & 0,001 \\
\hline Renda do municipio & $-0,0002$ & 0,000 & $-2,782$ & 0,008 \\
\hline Renda do governo municipal & $-0,0021$ & 0,001 & $-2,265$ & 0,028 \\
\hline Constante & 18,2220 & 4,245 & 4,292 & 0,000 \\
\hline
\end{tabular}

Fonte: Elaborado pelos autores.

correlacionado com os índices de crimes, revelando que aumentos de renda reduzem os indicadores de crimes. Deve-se ressaltar que o aumento da riqueza do município apresenta dois efeitos parciais e distintos sobre a criminalidade. O primeiro é que, com mais riqueza circulando pelo sistema, o campo de atuação dos criminosos se expande. O segundo efeito é que, quanto maior a riqueza, menor o incentivo que o indivíduo tem de migrar para o crime. Portanto, o 
fato de a criminalidade se correlacionar negativamente com a renda do município garante que o segundo efeito suplante o primeiro. Esse fato também reforça a adoção de políticas que aumentam a renda do município no combate à criminalidade. ${ }^{18}$

Como já era esperado, o nível de educação mostrou-se também estatisticamente significativo e negativamente correlacionado com a criminalidade em todas as modalidades de crimes consideradas, ${ }^{19}$ indicando que, quanto maior for a educação dos munícipes, menores serão os índices de crimes apresentados. Esse resultado reforça a importância dos investimentos governamentais em educação para o combate à criminalidade. Estudos mostram que, quanto maiores forem os níveis de escolaridade, maiores também serão os rendimentos do trabalho. De fato, maiores rendimentos reduzem os índices de crimes, pois aumentam os custos de migração das pessoas para as atividades criminosas. Além disso, a educação é um elemento importante que reduz as desigualdades de renda, reduzindo assim o ímpeto dos indivíduos migrarem para o crime.

O tamanho do governo municipal, cuja proxy utilizada foi a sua renda, mostrou-se também negativamente correlacionado com todos os índices de crime. Ressalta-se que essa variável foi estatisticamente significativa a $3 \%$ para o agregado de crimes e a $6 \%$ para as modalidades de furto e roubo e crimes contra o patrimônio. Isso significa que, quanto maior for a renda do governo municipal, menores serão os índices de criminalidade. Dessa forma, o princípio federalista, ao fortalecer os governos locais, contribui eficientemente para reduzir a criminalidade. É notório que, além dos tributos municipais arrecadados, tais como o imposto predial e territorial urbano (IPTU) e o imposto sobre serviços (ISS), o nível de renda do governo municipal depende fundamentalmente das transferências dos governos estadual e federal. O fundo de participação dos municípios, que é um repasse federal, representa para muitos municípios a maior parcela da sua receita. Para um bom número desses municípios, essa receita é a principal fonte de geração de emprego e renda para uma grande parcela dos munícipes, os quais acabam contendo o fluxo migratório para o crime.

18 Deve-se registrar que a evidência internacional tem mostrado uma correlação positiva entre o grau de desenvolvimento e a criminalidade. Com dados em cross section para vários paises, Soares (2001) demonstrou que grande parte dessa correlação é devida à correlação existente entre o próprio desenvolvimento econômico e a renda per capita, a qual apresentou correlação positiva com a atividade criminosa, principalmente no que concerne à modalidade específica de crime de roubo.

19 Deve-se frisar que essa variável foi estatisticamente significativa a $4 \%$ para o agregado de crimes. 
O modelo (4.8) foi estimado por máxima verossimilhança. A variação nos índices de criminalidade $\left(c_{t+k}-c_{t}\right)$, e a conseqüente definição da variável dummy, foi obtida tomando-se a média móvel de três anos, exceto para o início e o final das séries, onde tomou-se a média móvel de apenas dois anos..$^{20}$ Os resultados da estimação logística da probabilidade de variações nos índices de criminalidade encontram-se dispostos no Quadro 3.

Ressalte-se que a proporção de predições corretas do modelo para o índice de crime de furto e roubo foi de $83,7 \%$, a qual é uma média ponderada das proporções de acertos das probabilidades de respostas $\operatorname{Pr}(\mathrm{y}=1)$ de $85,7 \%$ e $\operatorname{Pr}(\mathrm{y}=0)$ de $82,1 \%$, o que representa uma boa aderência do modelo ao prever variações nesse índice de criminalidade. Aderência semelhante também foi obtida para o índice de crimes contra o patrimônio, com prediçóes corretas de $83,7 \%$, como média ponderada das proporções de acertos das probabilidades de respostas $\operatorname{Pr}(\mathrm{y}=1)$ de $81,8 \%$ e $\operatorname{Pr}(\mathrm{y}=0)$ de $85,2 \%$. No que concerne ao índice de crime agregado, a proporção de predições corretas do modelo foi de $85,7 \%$, a qual é uma média ponderada das proporções de acertos das probabilidades de respostas $\operatorname{Pr}(\mathrm{y}=1)$ de $90,3 \%$ e $\operatorname{Pr}(\mathrm{y}=0)$ de $77,8 \%$, o que representa uma boa aderência do modelo ao prever variações nesse índice de criminalidade. Devese ressaltar que todos os parâmetros estimados foram estatisticamente significativos e diferentes de zero, tanto pelo teste de Wald quanto pelo teste de verossimilhança, significando que essas variáveis são, de fato, importantes para explicar a probabilidade de variações nos índices de criminalidade.

Uma inspeção do Quadro 3 permite observar que, excetuandose a escolaridade, a concentração de renda e a renda do município, todas as outras variáveis consideradas na análise foram estatisticamente significativas (tanto pela estatística Wald quanto pela ótica da verossimilhança), no sentido de explicar a probabilidade de acréscimos nos índices de criminalidade na RMS. De fato, a eficiência da polícia, o grau de urbanização e a renda do governo municipal também se mostraram estatisticamente significativas em explicar a probabilidade de variações nos índices de criminalidade nessa região, assim como mantiveram o sinal observado anteriormente de suas correlações com os índices de criminalidade estudados. A densidade demográfica, a despeito de ter se correlacionado negativamente com os indicadores de criminalidade, mostrou uma correlação positiva com a probabilidade de variações nos índices de criminalidade.

so Esse procedimento objetivou não reduzir consideravelmente o tamanho da amostra. 
Quadro 3: Resultados dos modelos logit da probabilidade de variações nos índices de criminalidade na RMS

\begin{tabular}{|c|c|c|c|c|c|c|}
\hline \multirow{2}{*}{ Variáveis } & \multirow{2}{*}{$\beta$} & \multicolumn{2}{|c|}{ Teste de Wald } & \multicolumn{3}{|c|}{ Teste de Verossimilhança } \\
\hline & & Valor & Sig Wald & $\begin{array}{ll}\text { Log } \\
\text { Likelihood }\end{array}$ & $-2 \log$ LR & Sig LR \\
\hline \multicolumn{7}{|l|}{ FURTO E ROUBO } \\
\hline LCrime(-1) & $-12,339$ & 6,886 & 0,029 & $-27,176$ & 22,415 & 0,000 \\
\hline LEficiência da polícia & $-2,789$ & 6,930 & 0,061 & $-23,923$ & 15,910 & 0,000 \\
\hline LDensidade demográfica & 1,934 & 4,580 & 0,032 & $-20,700$ & 9,463 & 0,002 \\
\hline LRenda do governo & $-1,999$ & 4,775 & 0,029 & $-20,122$ & 8,308 & 0,004 \\
\hline Constante & 86,570 & 6,627 & 0,010 & & & \\
\hline \multicolumn{7}{|c|}{$N=50 ; \quad P(y=1)=85,7 \% ; \quad P(y=0)=82,1 \% ; \quad P=83,7 \%$} \\
\hline \multicolumn{7}{|c|}{ CRIMES CONTRA O PATRIMÔNIO } \\
\hline LCrime $(-1)$ & $-6,128$ & 7,726 & 0,005 & $-28,349$ & 13,867 & 0,000 \\
\hline LEficiência da polícia & $-1,700$ & 7,596 & 0,006 & $-27,249$ & 11,666 & 0,000 \\
\hline LGrau de urbanização & 6,629 & 3,145 & 0,076 & $-23,526$ & 4,221 & 0,040 \\
\hline LDensidade demográfica & 1,160 & 5,450 & 0,020 & $-25,843$ & 8,854 & 0,003 \\
\hline LRenda do governo & $-0,965$ & 3,278 & 0,070 & $-23,275$ & 3,718 & 0,054 \\
\hline Constante & 41,091 & 6,144 & 0,013 & & & \\
\hline \multicolumn{4}{|c|}{$N=50 ; \quad P(y=1)=81,8 \%$} & \multicolumn{3}{|c|}{ Signific $=0.000$} \\
\hline \multicolumn{7}{|c|}{ CRIME AGREGADO } \\
\hline LCrime $(-1)$ & $-6,601$ & 8,684 & 0,003 & $-23,566$ & 12,566 & 0,000 \\
\hline LEficiência da policia & $-1,251$ & 9,952 & 0,002 & $-20,107$ & 5,666 & 0,022 \\
\hline LGrau de urbanização & 11,076 & 6,761 & 0,009 & $-21,530$ & 8,122 & 0,004 \\
\hline LDensidade demográfica & 2,208 & 9,952 & 0,002 & $-28,122$ & 21,307 & 0,000 \\
\hline Constante & 41,091 & 6,144 & 0,013 & & - & - \\
\hline
\end{tabular}

Fonte: Elaborado pelos autores.

De especial interesse é o fato de que todos os índices de criminalidade defasados tenham se mostrado estatisticamente significativos e negativamente correlacionados com as respectivas probabilidades de variação em seus índices de crime. Esse fato é confirmado tanto pela estatística Wald quanto pela de verossimilhança, as quais se mostraram estatisticamente significativas. Isso significa que os níveis de criminalidade apresentam um efeito amortecedor no crescimento dos mesmos, de modo que, quanto maior for o nível de criminalidade hoje, menor será a probabilidade de aumentos nos índices de crimes amanhã. Esse resultado não abre apenas a possibilidade para estabelecer medidas de curto prazo de combate à 
criminalidade, amortecendo ou refreando seus indicadores, mas principalmente evidencia uma certa importância destas no sentido de conter imediatamente a probabilidade de futuros aumentos dos indicadores de criminalidade através do tempo. Esse resultado, bem animador, difere daquele obtido por Carrea-Fernandez $\mathcal{E}$ Pereira (2001), que constatou que o nível de crimes causa um preocupante efeito multiplicador (ou inércia) na probabilidade de variação dos índices de criminalidade.

O Quadro 3 mostra ainda que a eficiência da polícia e a renda do governo municipal, por apresentarem correlação negativa com a evolução da criminalidade, são estatisticamente significativas no sentido de conter a probabilidade de aumentos em todos os indicadores de criminalidade na RMS. Exceção deve ser feita à renda do governo, a qual não se mostrou efetiva em conter a probabilidade de aumentos no agregado de crimes $^{21} \mathrm{e}$, por isso mesmo, não consta da relação de variáveis explicativas no último bloco do Quadro 3. Esse resultado confirma que quanto maiores forem a eficiência do aparato policial e a renda do governo municipal, menores serão as probabilidades de aumentos nos índices de criminalidade dessa região. Dessa forma, por ter capacidade de reduzir a probabilidade de aumentos nos índices de criminalidade, a renda do governo municipal deve ganhar uma importância adicional nas políticas públicas de combate ao crime.

Finalmente, o grau de urbanização e a densidade demográfica, ao se mostrarem estatisticamente significativos e positivamente correlacionados com a evolução da criminalidade, contribuem para aumentar a probabilidade de incrementos nos índices de criminalidade. A maior concentração demográfica, principalmente nas áreas urbanas, ao favorecer a proliferação de bolsões de pobreza, contribui para aumentar significativamente a probabilidade de crescimento dos índices de criminalidade na RMS.

21 O impacto da renda do governo municipal que se verificou no sentido de reduzir a probabilidade de aumentos no crime de furto e roubo e contra o patrimônio, mas não sobre o agregado de crimes, parece inconsistente, ao mostrar efeitos diferenciados sobre esses dois índices de criminalidade. Essa inconsistência é mais aparente do que real, tendo em vista que no agregado de crimes estão computadas todas as ocorrências não criminais, tais como acidentes de trânsito e tumultos, certas contravenções penais e crimes menores, que ocorreriam independentemente dessa renda. 


\section{Conclusões e considerações finais}

Objetivando ampliar o conhecimento a respeito da atividade criminal na Região Metropolitana de Salvador (RMS), analisou-se a evolução dos principais indicadores de crimes, entre eles os índices de crime de furto e roubo, crimes contra o patrimônio e o agregado de crimes, no período de 1993 a 1999, assim como comparou-se a evolução desses índices no quadriênio de 1996-99, em relação àqueles observados no triênio de 1993-95.

Uma análise preliminar dos dados revelou que a RMS apresenta altos índices de criminalidade, colocando-a entre as regiões de maior incidência de índices de criminalidade do país e do mundo. A RMS apresentou, no quadriênio 1996-99, índices de 14,18 por mil habitantes para a modalidade de crime de furto e roubo e de 23,77 por mil habitantes para o agregado de crimes. Ao comparar-se o índice médio de crime de furto verificado na RMS com outras regiões, que tradicionalmente apresentam graves problemáticas de criminalidade, como é caso de São Paulo, constata-se que o índice verificado na RMS é ainda maior. Enquanto o índice médio de crime de furto na Regiāo Policial da Grande São Paulo, que em 1995 foi de 7,89 por mil habitantes, a RMS apresentou, nesse mesmo ano, um índice de furto de 10,83 por mil habitantes. O índice médio de furto na RMS é ainda maior que aqueles registrados em Chicago $(10,68)$, Detroit $(9,83)$, São Francisco $(8,66)$, Los Angeles $(8,15)$ e Nova York $(8,14)$, cidades consideradas tradicionalmente problemáticas em termos de criminalidade.

Como agravante, a análise também revelou que, para algumas modalidades de crimes, os índices de criminalidade na RMS apresentaram uma tendência de crescimento, estabelecendo uma situação extremamente preocupante em termos de segurança pública. A preocupação aumenta na medida que se constata que esses índices cresceram mais nos municípios que apresentaram os menores índices de criminalidade, principalmente em Salvador, município maior e mais importante da RMS, revelando que a criminalidade tende a se uniformizar em todos os municípios da RMS pelo seu nível mais alto. No entanto, esse resultado deve ser visto com cautela, tendo em vista que em Salvador, maior município da RMS, grande parte das ocorrências policiais não é registrada, prática motivada pelo descrédito dos cidadãos na sua polícia. Em contrapartida, nos municípios menores, onde o aparato policial exerce uma maior integração com seus munícipes, estes acabam registrando sistematicamente suas ocorrências policiais. 
Ao analisar a evolução das principais correntes do pensamento sobre o fenômeno da criminalidade, este ensaio mostrou que a criminalidade não pode estar dissociada dos fatores demográficos e econômicos, em seus múltiplos problemas estruturais e conjunturais. Assim, tentando avaliar a importância empírica de variáveis socioeconômicas na explicação desse fenômeno, este trabalho desenvolveu um modelo econométrico baseado em curvas de oferta de atividades criminosas, buscando na teoria econômica do crime as bases para a sua sustentação. Os resultados econométricos iniciais mostraram que aumentos na densidade demográfica, melhoria dos níveis de eficiência da polícia e de educação, expansões das rendas do município e do governo municipal, assim como reduções da concentração de renda e do grau de urbanização, contribuem significativamente para reduzir a atividade criminosa na RMS.

Os resultados econométricos mostraram, ainda, que, quanto maior for o nível de criminalidade, menor será a probabilidade de aumentos nos índices de crimes, evidenciando que os níveis de criminalidade apresentam um efeito amortecedor no crescimento dos mesmos. Esse resultado possibilita estabelecer medidas de curto prazo que possam combater eficazmente a criminalidade, amortecendo ou refreando seus indicadores através do tempo. É óbvio que a aplicação dessas medidas não pode prescindir da vontade política dos governantes, mas principalmente da sociedade como um todo.

A densidade demográfica, a despeito de ter se correlacionado negativamente com os indicadores de criminalidade, mostrou uma correlação positiva com a probabilidade de variações nos índices de criminalidade, revelando que os municípios com maior densidade demográfica são também aqueles que apresentam as maiores probabilidades de aumentos em seus indicadores de criminalidade. Esse resultado vem reforçar o efeito perverso de aumentos no grau de urbanização tanto sobre o aumento do nível de criminalidade, detectado anteriormente, quanto sobre o crescimento da probabilidade de aumentos nos indicadores de crime. Esse resultado abre novas perspectivas para as políticas que favorecem a fixação da população no campo ou estabelecem condições para redirecionar as pessoas para as áreas rurais, como é o caso específico da reforma agrária.

Além do mais, os resultados deste estudo revelaram que a melhoria da eficiência da polícia, além de conter os níveis de criminalidade, também se mostrou estatisticamente significativa em conter a probabilidade de aumentos nos indicadores de crimes na RMS. Resultado semelhante foi verificado em relação à renda do 
governo municipal, revelando que aumentos do nível de renda do governo municipal reduzem tanto os níveis de criminalidade quanto a probabilidade de aumentos nos índices de criminalidade nessa região. Assim, ao reduzir a probabilidade de aumentos nos índices de criminalidade, a renda do governo municipal deve ganhar uma importância adicional nas políticas públicas de combate ao crime. Essa evidência permite concluir que o fortalecimento dos governos locais, apregoado pelo princípio federalista, mostra-se eficazmente apropriado para reduzir a criminalidade na RMS.

Ao produzir algum conhecimento acerca da criminalidade na RMS, espera-se que os resultados obtidos neste estudo possam, de alguma forma, contribuir para que esse fenômeno seja encarado com mais seriedade pelo setor público. Não é necessário que a criminalidade atinja índices alarmantes e gere mais insegurança para que as autoridades públicas e a sociedade de um modo geral passem a levar esse fenômeno com mais determinação e seriedade. Ademais, espera-se que este trabalho desperte no meio científico interesse suficiente a ponto de induzir novos estudos, ampliando assim os conhecimentos acerca da criminalidade. É com suficiente conhecimento desse importante fenômeno social que a comunidade será capaz de gerar ambientes mais seguros para o convivio social de seus cidadãos.

\section{Referências bibliográficas}

ARAÜJO JR., Ari F.; FAJNZYLBER, Pablo. Crime e economia: um estudo das micro regiões mineiras. Campinas: XXVIII Encontro Nacional de Economia da ANPEC, 2000.

BECKER, Gary S. Crime and punishment: an economic approach. Journal of Political Economy, v. 76, n. 1, p. $169-217,1968$.

BERON, Kurt $J$. Applying the economic model of crime to child support enforcement: a theoretical and empirical analysis. The Review of Economics and Statistics, v. 27, p. $382-$ 390, Jan. 1988.

CARRERA-FERNANDEZ, José. A Economia do crime revisitada. Economia e Tecnologia, V.1, n. 3, p. 305-318, Campinas: 1998.

CARRERA-FERNADEZ, José; MALDONADO, Genaro E. C. A Economia do narcotráfico: uma abordagem a partir da experiência boliviana Nova Economia, v. 09, n. 02, p. 137 173, Belo Horizonte: 1999.

CARRERA-FERNANDEZ, José; PEREIRA, Rogério. A economia do crime: uma abordagem a partir da Região Policial da Grande São Paulo. Campinas: XXVIII Encontro Nacional de Economia da ANPEC, 2000.

CARRERA-FERNANDEZ, José. A repressão militar e a mudança estrutural na relação entre o diferencial de ganho e a migração para o setor do narcotráfico: o caso da Bolivia. Revista Econômica do Nordeste, v. 32, n. 3, Fortaleza: 2001.

CARRERA-FERNANDEZ, José; PEREIRA, Rogério. Diagnóstico da criminalidade na Bahia: uma análise a partir da economia do crime. Revista Econômica do Nordeste, v. 32, n. Especial, p. 290 - 307, Fortaleza: 2001. 
CAVALO, Guillermo A.; MENDOZA, Enrique G. Petty crime and cruel punishment: lessons from Mexican debacle. American Economic Review, v. 186, n.2, May 1995.

CORNWELL, Christopher; TRUMBULL, William N. Estimating the economic model of crime with panel data. The Review of Economics and Statistics, v. 30, p. 360-66, 1993.

DAVIS, Michael L. Time and punishment: an intertemporal model of crime. Journal of Political Economy, v. 96, n. 2, p. 383-90, 1988.

DIUILIO, John J. Jr. Crime and punishment: an economic approach. Journal of Economics Perspectives, v. 10, n. 1, p. 3- 24, Winter 1996.

EHRLICH, Isaac. On the usefulness of controlling individuals: an economic analysis of rehabilitation, incapacitation, and deterrence. American Economic Review. v. 71, n. 3, p. 307-322, Jun. 1971.

Participation in illegitimate actives: a theoretical and empirical investigation. Journal of Political Economy, v. 81, p.521 - 563, 1973.

. The deterrent effect of capital punishment: a question of life and death. American Economic Review, v. 65, p.397-417, 1975.

Crime, punishment, and the market for offenses. Journal of Economic Perspectives, v. 10, n. 1, p. $43-67,1996$.

EHRLICH, Isaac; BECKER, Gary S. Market insurance, self-insurance, and self protection. Journal of Political Economy, v. 78, p. 623 - 48, July/ August, 1972.

EHRLICH, Isaac; BROWER, George D. Deterrence and enforcement of laws: on issue of causality in economic model of crime and law enforcement - some theoretical considerations and experimental evidence. American Economic Review. v. 77, n. 02, p. 99 - 106, May 1987.

EIDE, Erling. Enclyclopedia of Law and Economics. Disponível em: < encyclo.findlaw.com/lit/8100art.html > Acesso em: 08 de abr. 2005.

FAJNZYLBER, Pablo; ARAUJO JR, Ari F. Violência e Criminalidade. In: LISBOA, M. B. e MENEZES-FILHO, N. A. (Orgs.). Microeconomia e sociedade no Brasil. Rio de Janeiro: FGV, 2001.

FREEMAN, Richard $B$. Why do so many young American men commit crimes and what might we do about it? Journal of Economic Perspectives, v. 10, n. 1, p, 25-42, winter, 1996.

FUKUYAMA, Francis. A grande ruptura: uma revolução silenciosa que já começou. $O$ Estado de São Paulo, São Paulo, 30 de maio de 1999. Caderno2/Cultura, d-3 a d-7.

FURLONG, William J. A General equilibrium model of crime commission and prevention. Journal of Public Economics, v. 34, p. 87 - 103, North-Holland, 1987.

GLAESER, Edward L; SACERDOTE, Bruce; SCHEINKMAN, José. "Crime and social interactions". The Quarterly Journal of Economics", v. 61, n. 2, p. 507- 548, 1996.

GREENE, William H. Econometric analysis. Third Edition. New Jersey: Prentice Hall, 1073 p. 1997.

GROGGER, Jeffrey. Certainty Vs. Severity of punishment. Economic inquiry, v. XXIX, p. 297-309, April, 1991.

The effect of arrests on the employment and earnings of young men. The Quarterly Journal of Economics, p. 51 - 71, February 1995.

KIM, Il- Joong, BENSON, Bruce L., RASMUSSEN, David W., ZUEHLKE, Thomas W. An economic analysis of recidivism among drug offenders. Southern Economic Journal, v. 56, n. 01, out. 1989.

LANG, Kevin; BELL, Duran. An economic model of the intake disposition of juvenile offenders. Journal of Public Economics. North-Holland, v. 32, p. 79-99, 1987. 
LEUNG, Siu Fai. Dynamic deterrence theory. Economica, v. 62, p. 65-87, 1995.

LEVIT, Steven D. The effect of prison population size on crime rates: evidence from prison overcrowding litigation. The Quarterly Journal of Economics, v. CXI, n. 02, p. $319-$ 351, 1996.

MAGALHÄES, Tatiana A. Desemprego e crime - uma análise de séries de tempo para o Distrito Federal: 1992 - 1996. Brasília, 1997, 46 p. Tese (Mestrado). Departamento de Economia - Universidade de Brasília.

MYERS, Samuel L. Jr. Estimating the economic model of crime employment versus punishment effects. Quarterly Journal of Economics. vol. XCVIII, n. 01, p. 157-175, 1983. PEREIRA, Rogério. A criminalidade na Região Policial da Grande São Paulo. Curso de Mestrado em Economia - Universidade Federal da Bahia. Dissertação de Mestrado, 2000.

PEREIRA, Rogério; CARRERA-FERNANDEZ, José. A criminalidade na Região Policial da Grande São Paulo sob a ótica da economia do crime. Revista Econômica do Nordeste, v. 31, n. Especial, p. 898-918, novembro de 2000.

SAH, Raaj K. Social osmosis and patterns of crime. Journal of Political Economy, Chicago, V. 99, n. 6, p. $1272-1295,1991$.

SOARES, Rodrigo Reis. Development, crime, and punishment: accounting for the international differences in crime rates. Chicago: The University of Chicago, April, 2001. STIGLER, George J. The Optimum enforcement of laws. Journal of Political Economy, v. 83, p. 526-36, May/June, 1970.

TRUMBULL, William N. Estimations of economic model of crime using aggregate and individual level data. Southern Economic Journal, v. 56, n. 02, p. 423 - 439, out. 1989.

WTTTE, Ann Dryden. Estimating the economic model of crime with individual data. Quarterly Journal of Economics, v. XLIV, n. 01, p. 57-83, 1980.

WONG, Yue-Chim Richard. An Economic analysis of the crime rate in England and Wales, 1857-92. Economica, v. 62, n. 246, p. 235-246, May 1995.

WYNARCZYK, Peter. Economic Affairs. Oxford: Institute of Economic Affairs, p. 02-04, September, 2000. 